\title{
WestVirginiaUniversity
}

THE RESEARCH REPOSITORY @ WVU

Graduate Theses, Dissertations, and Problem Reports

2014

\section{Animal dispersal of American ginseng (Panax quinquefolius L.)}

Amy M. Hruska

West Virginia University

Follow this and additional works at: https://researchrepository.wvu.edu/etd

\section{Recommended Citation}

Hruska, Amy M., "Animal dispersal of American ginseng (Panax quinquefolius L.)" (2014). Graduate Theses, Dissertations, and Problem Reports. 615.

https://researchrepository.wvu.edu/etd/615

This Thesis is protected by copyright and/or related rights. It has been brought to you by the The Research Repository @ WVU with permission from the rights-holder(s). You are free to use this Thesis in any way that is permitted by the copyright and related rights legislation that applies to your use. For other uses you must obtain permission from the rights-holder(s) directly, unless additional rights are indicated by a Creative Commons license in the record and/ or on the work itself. This Thesis has been accepted for inclusion in WVU Graduate Theses, Dissertations, and Problem Reports collection by an authorized administrator of The Research Repository @ WVU. For more information, please contact researchrepository@mail.wvu.edu. 
Animal dispersal of American ginseng (Panax quinquefolius L.)

\author{
Amy M. Hruska \\ Thesis submitted to the \\ Eberly College of Arts and Sciences \\ at West Virginia University
}

in partial fulfillment of the requirements for the degree of

Master of Science

in

Biology

Committee:

James B. McGraw, PhD, Chair

Stephen DiFazio, PhD

Petra Bohall Wood, PhD

Department of Biology

Morgantown, West Virginia

2014

Keywords: American ginseng, wood thrush, small mammals, seed dispersal, seed predation Copyright 2014 Amy M. Hruska 


\title{
ABSTRACT \\ Animal dispersal of American ginseng (Panax quinquefolius L.)
}

\begin{abstract}
Amy M. Hruska
American ginseng (Panax quinquefolius L.) is a long-lived forest herb found throughout Appalachia, well-known for its reputation as a medicinal plant species. Harvest of ginseng for the international medicinal plant trade has been a significant contributor to population decline of the species. As a declining species with life-history traits similar to many other herbaceous perennials and both cultural and economic value, American ginseng has become a focal species for many demographic and conservation based studies. Seed dispersal is a critical component of ginseng demography lacking empirical evidence for potential dispersal mechanisms. To date, gravity is considered to be the primary mechanism of dispersal, but the production of red, fleshy berries during the late fall suggest animal dispersal. Based on berry morphology, timing of ripening, and field-based observations, songbird and small mammal species were determined to be two likely candidates for ginseng dispersal. In Chapter 2, I investigated the frequency and type of songbird species interacting with ginseng berries using infrared, motion-activated wildlife cameras in the field and observed songbird digestive behavior in captivity. Thrushes were found to most frequently remove berries in the field and regurgitate viable seeds, on average, 16 minutes after ingestion. In Chapter 3, small mammal interactions were investigated using infrared, motion-activated wildlife cameras and cafeteria-style feeding boxes in the field. In addition, the impacts of high tree mast years, an environmental event linked to small mammal population dynamics, on seedling recruitment was investigated using historical mast indices and long-term ginseng population data. Small mammals more frequently interacted with ginseng berries in camera images compared to thrushes and mice were observed to predate ginseng seeds during feeding trials. The impacts of high tree mast years were found to differ between sites, but recruitment was found to decrease with increasing mast production at four sites. Overall, thrushes were found to be the primary animal disperser of American ginseng while small mammals are most often seed predators. As the primary animal disperser, thrushes provide the first documented opportunity for intermediate and long distance dispersal events. Dispersal events over such distances are becoming increasingly more important for ginseng to persist in the presence of intense harvest, deer browse, and climate change; three significant factors contributing to declining ginseng populations. Additionally, small mammal predation of ginseng seeds could further contribute to population declines.
\end{abstract}




\section{Acknowledgements}

First and foremost, I would like to thank my adviser Dr. James McGraw for this opportunity. Jim is a terrific adviser and was always available and happy to provide support and guidance in order to help me become a better scientist. Working in his lab was a privilege and this research would not have been possible without him. I would also like to thank my committee, Dr. Petra Bohall Wood and Dr. Stephen DiFazio, for their advice and assistance during this process.

I am also very grateful for my fellow lab members, and good friends, Jennifer L. Chandler and Jessica B. Turner. Both Jen and Jessi Brie were always there for support, whether I needed help in the field, reviewers, or an audience to rehearse a presentation. I would also like to thank former lab member, Dr. Sara Souther, who began using wildlife cameras in the field to investigate ginseng disperser mechanisms and assisted with edits. Additionally, this work would not have been possible without the assistance of our undergraduate interns, Alixandra Wagner, Michael Elza, and Chris Mallow, who were invaluable during my fall field seasons.

Finally, I would like to thank my friends and family. The support that I have received from members of the WVU Biology Department (fellow graduate students, faculty, and staff alike) has really truly made this a wonderful experience. Also, I am grateful to all of my friends who have always been a phone call away to lend a supportive ear. Furthermore, I would not have made it this far without the love and support of my parents, David and Karen, and my siblings, Ryan and Kailey. My family has always believed in me and given me the courage to never settle for anything less than my best. I promise to always reach, if not raise, the standards that they've seen me set for myself and hope that I always make them proud. 


\section{TABLE OF CONTENTS}

LIST OF TABLES ........................................................................................................................................ 1

LIST OF FIGURES .............................................................................................................. 2

CHAPTER 1: GENERAL INTRODUCTION ........................................................................ 4

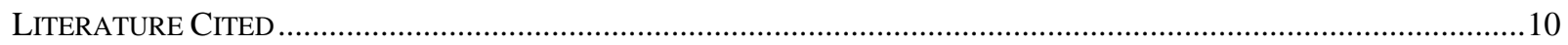

CHAPTER 2: SONGBIRD DISPERSAL OF AMERICAN GINSENG (PANAX

QUINQUEFOLIUS L.) .................................................................................................................... 14

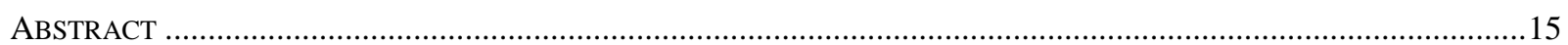

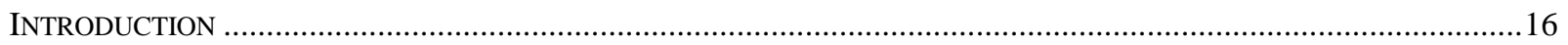

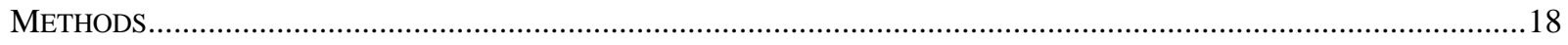

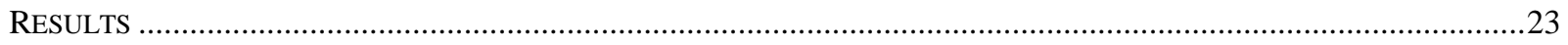

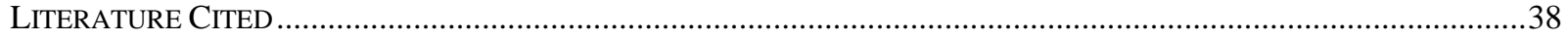

CHAPTER 3: SMALL MAMMAL SEED PREDATION OF AMERICAN GINSENG

(PANAX QUINQUEFOLIUS L.)....................................................................................................... 45

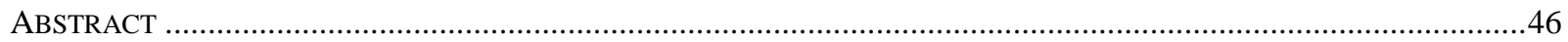

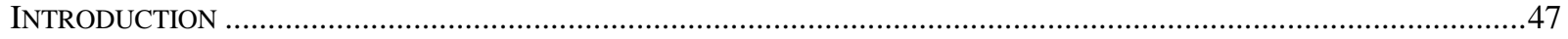

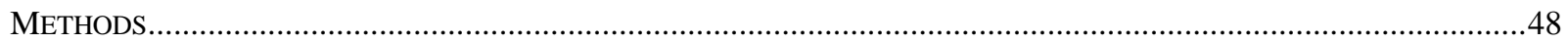

RESULTS …

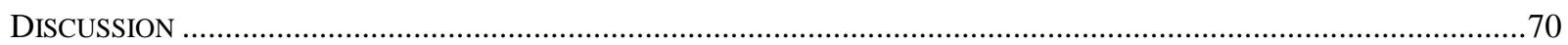

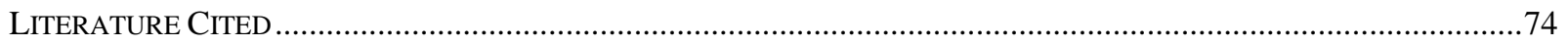

CHAPTER 4: GENERAL CONCLUSIONS................................................................................ 80

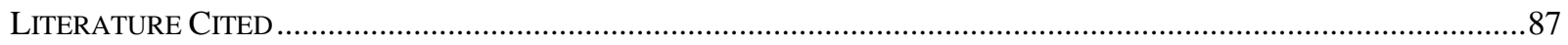




\section{List of Tables}

Table 2.1. Levels of Interaction. Each event, made up of a series of three images per IR-motion activated occurrence, was assigned a quantitative value to represent the level of interaction a potential disperser (PD) had with American ginseng berries.

Table 2.2. The total number of events for each mammalian and avian species per levels of interaction.

Table 2.3. The total number of berries removed per camera location as a direct result or following a Level 4 or 5 Interaction with a potential disperser and the species responsible for the berry removal at each camera location.

Table 3.1. Levels of Interaction, adapted from Hruska et al. (in review). Each event, a series of three images per IR-motion activated camera trigger, was assigned a quantitative value to represent the level of interaction a potential disperser (PD) had with American ginseng berries.

Table 3.2. Table of regression results for the twenty regressions comparing seedling recruitment indices $(\mathrm{y})$ to hard mast indices $(\mathrm{x})$ for seeds produced the year of a mast $(\mathrm{t})$ and the year following a mast $(\mathrm{t}+1)$. 


\section{List of Figures}

Figure 2.1. Partitioning of avian and mammalian potential disperser events based on categories that would least likely result in a dispersal event (LLI: Low Level of Interaction) and most likely result in a dispersal event (HLI: High Level of Interaction).

Figure 2.2. A. Image of an Eastern chipmunk demonstrating High Level Interaction behavior by touching the ginseng infructescence, B. Image of a wood thrush demonstrating High Level Interaction behavior with a berry in its beak. C. Image of a hermit thrush demonstrating High Level Interaction behavior with a berry in its beak. D. Image of a Swainson's thrush demonstrating High Level Interaction behavior with a berry in its beak.

Figure 2.3. Partitioning of thrush and non-thrush potential disperser events based on categories that would least likely result in a dispersal event (LLI: Low Level of Interaction) and most likely result in a dispersal event (HLI: High Level of Interaction) with the proportion of species within each category.

Figure 3.1. Map of WV regions used for mast surveys; regions were labeled 1-5. Starred counties represent the six counties where the twelve long term populations are located (Peters et al. 2011): 5 populations in Tucker County, 2 in Monongalia County, 1 in Marion County, 1 in Kanawha County, 1 in Greenbrier County, and 1 in Mercer County.

Figure 3.2. Diagram depicting the procedure for investigating the relationship between seedling recruitment of seeds produced both during and the year immediately following a given mast year with the average hard mast index at each population.

Figure 3.3. Game camera images displaying an Eastern chipmunk exhibiting High Level Interaction behavior. A. Eastern chipmunk has pulled ginseng plant to the ground via the 
infructescence. B and C. Eastern chipmunk sits below the ginseng plant with a suspected berry in its paws.

Figure 3.4. Partitioning of thrush and squirrel potential disperser events based on categories that would least likely result in a dispersal event (LLI: Low Level of Interaction) and most likely result in a dispersal event (HLI: High Level of Interaction), when foraging behavior is included as a HLI.

Figure 3.5. The total number of boxes visited at both NY and WV sites over a six day period in 2012 and a five day period in 2013.

Figure 3.6. Food item selection at NY and WV sites in 2012 and 2013. Number of food items taken refers to the number of food items either eaten within the box or removed from the box. NY sites are differentiated in 2013 because the number of food items taken depended on the site.

Figure 3.7. Images of mice feeding behavior within box. A. Still image from video camera of mouse masticating ginseng berry. B. Ginseng pulp and seed coat remnants found along the bottom of a feeding box with seed embyros missing. C. Ginseng pulp and seed coat remnants in ginseng feeding tray.

Figure 3.8. Yearly seedling recruitment indices regressed against the percent difference of the yearly average mast indices compared to the historical average index. A. Yearly seedling recruitment indices at WV 27 as a function of the percent difference of oak mast indices. B. Yearly seedling recruitment indices at WV26 as a function of percent difference of oak mast. C. Yearly seedling recruitment indices at WV22 as a function of percent difference of beech mast. D. Yearly seedling recruitment indices at WV30 as a function of percent difference of black cherry mast. 
Chapter 1: General Introduction 
American ginseng (Panax quinquefolius L.) is a forest understory herb found throughout Appalachia, well-known for its reputation as a medicinal plant species. Once an abundant understory species, today ginseng is considered to be uncommon to rare (McGraw et al. 2003; McGraw et al. 2013). Harvest of ginseng roots for the international medicinal plant trade since the 1700's is considered to have largely contributed to the decline of the species (Johannsen 2006; McGraw et al. 2013). Concerns due to overharvest led to ginseng being listed on Appendix II of the Convention on International Trade in Endangered Species of Wild Flora and Fauna (CITES) in 1975, regulating the export of roots outside of the United States (Robbins 2000). Today, hundreds of thousands of roots are still harvested annually for export from the United States (USFWS 2013), contributing to further, rapid population decline (McGraw et al. 2013). Additionally, American ginseng has a life cycle similar to many other perennial forest herbs. Ginseng is a slow-growing, long-lived herb $(50+y r s)$ that is distributed within the forest across a broad ecological niche (Lewis and Zenger 1982; McGraw et al. 2003). An annual aboveground stalk emerges in May and senesces in October, while yearly fixed carbon is primarily stored in a belowground rhizome (Lewis and Zenger 1982; Anderson 1993).

With the unique status as a plant species of economic importance, with rapidly declining populations, and a life-cycle similar to many other perennial forest herbs, American ginseng has become a model species for many demographically, environmentally, and conservation based questions (reviewed in McGraw et al. 2013). Many studies have focused on how various environmental factors influence the performance of individual plants (e.g., Furedi and McGraw 2004, Wixted and McGraw 2009) and how harvest affects population growth (e.g.Van der Voort and McGraw 2006, Mooney and McGraw 2009). However, an important component of ginseng conservation and demography that has not been well documented is the impacts of animal 
interactions with ginseng berries. Animal interactions with fruits directly impact the fate of seeds within plant populations and most often result in one of two outcomes: a seed dispersal event or a seed predation event (Hulme 2002). To date, the only scientifically documented animal interaction with ginseng has been the browse of plants by white-tailed deer (Odocoileus virginianus), which results in a seed predation event when seeds are consumed (Furedi and McGraw 2004, McGraw and Furedi 2005). However, ginseng produces bright, red fleshy berries beginning at the end of August which suggests that other animals might also interact with and potentially disperse a proportion of the seeds (Howe and Smallwood 1982; McGraw et al. 2005). Determining what animal species interact with ginseng berries and seed fate after an interaction identifies potential mechanisms for seed dispersal or potential additional threats to population growth via seed predation (Fenner 2000).

Seed dispersal can be a significant contributor to the immigration and emigration of individuals to and from a population, influencing both the spatial distribution and genetic population structure of a species (Cousens et al. 2008). Dispersal increases the distance between genetically similar individuals (i.e. parent and sibling plants), thereby reducing competition, disease transmission, and other interspecific interactions between related individuals (Augsperger 1984). The transportation of seeds from areas of high competition to areas of lower competition enhances germination rates and seedling survival, both increases connectivity between populations and population sizes at the metapopulation level (Bohrer et al. 2005). Particularly, rapid dispersal to previously unoccupied suitable habitats decreases the probability of extinction at the metapopulation level for species at intermediate local-extinction levels (Bohrer et al. 2005). Seed dispersal also plays an integral role in a plant species' resiliency to environmental conditions that may otherwise impact overall fitness (Trakhtenbrot et al. 2005). 
Ginseng is a species adapted to local temperature conditions, and is threatened by a rapidly changing climate (Souther and McGraw 2011, McGraw et al. 2013). Seed dispersal over longer distances only achieved via animal-facilitated dispersal events could provide the necessary gene flow between locally-adapted populations to prevent rapid population decline (Souther and McGraw 2011, Souther and McGraw in press). Concerns have been raised over the potential impacts of climate change on species distributions, including ginseng, and have called attention to the increasing need to understand dispersal mechanisms in order to predict future distributions (e.g.Pearson \& Dawson, 2003; Thuiller et al. , 2008; Engler \& Guisan, 2009; Souther \& McGraw 2011).

In contrast to seed dispersal events, seed predation events render seeds inviable and may negatively impact populations. Seed predation can have significant consequences for plant populations by decreasing the number of seeds that enter the seed bank and ultimately the total number of new individuals introduced into a population (Fenner 2000). To date, browse by white-tailed deer is the only well-document animal-ginseng interaction (Furedi and McGraw 2004, McGraw and Furedi 2005, McGraw et al. 2013). Deer may ingest all aboveground parts of ginseng during browse events and seeds become inviable after ingestion (Furedi and McGraw 2004). Demographic analyses of browse on ginseng populations have identified intense browse to negatively impact the viability of ginseng populations and is considered to be one of the main threats contributing to population declines (Furedi and McGraw 2004, McGraw and Furedi 2005, McGraw et al. 2013).

Individuals within ginseng populations are spatially characterized by a clustered distribution that suggests limited dispersal between populations (Cruse-Sanders and Hamrick 2004). In addition, previous work investigating seed movement also demonstrated that $90 \%$ of 
fruits placed along the forest floor moved two meters or less (Van der Voort 2005). However, the ripening of ginseng seeds in the late summer/early fall, could make them a food source for a variety of animals, such frugivorous songbirds prior to migration (Stile 1980; Izhaki and Safriel 1989) or foraging small mammals before the winter (Elliot 1978). In addition, various animal species, such as songbirds, chipmunks, and turkeys, have been anecdotally observed to interact with ginseng berries (Pritts 2010). Previous experimental work by Souther and McGraw (20072010) demonstrated that animal-ginseng interactions could be observed using infrared, motionactivated wildlife game cameras. Utilizing images collected from those years, and continuing to use wildlife cameras to observe animal-ginseng interactions (2011-2013), I categorized the images by assigning them a "Level of Interaction" to determine how "intimately" animal species interacted with ginseng berries (Table 2.1).

In Chapter 2, based on berry and seed phenology and morphology and preliminary camera observations, I focused my analysis of these images on songbird-ginseng interactions and asked: (1)What is the frequency of avian interactions with ginseng berries? (2) How do avian interactions compare to mammalian interactions? (3)Of the avian interactions, what species of songbirds most frequently interacts with ginseng berries? In Chapter 2, I also conducted feeding trials in order to determine (4) Do songbirds that interact with ginseng berries defecate or regurgitate viable seeds? (5) How long do ginseng seeds stay within a songbird's digestive system?

In Chapter 3, I investigated small mammal interactions with ginseng based on High Level Interactions observed during image analysis as well as observed seedling caches in the field. Utilizing images from wildlife cameras, I asked: (1) What species of small mammals frequently interact with ginseng berries? (2) How do small mammal interactions compare to frequent 
songbird interactions? Additionally, using cafeteria-style feeding boxes in the field to observe feeding behaviors, I asked: (3) Do small mammals primarily ingest or scatter hoard berries? (4) If ingested by small mammals are seeds still viable? (5) If removed from the box, how far do small mammals carry ginseng seeds and what is the fate of these seeds? Furthermore, since small mammal populations are known to fluctuate in response to fluctuation in mast years (Wolff 1996), I used seedling recruitment data from long-term census data to yearly hard mast indices to ask: (6) Does seedling recruitment differ following an increase in hard mast fruits?

With these combined studies, the overall goal of my thesis was to characterize frequent animal interactions with American ginseng and determine how these interaction impact individual seed fates and overall population dynamics. Determining the consequences of frequent animal interactions with ginseng seeds provides a more comprehensive understanding of ginseng demography and provides a stronger framework for conservation. This data in combination with current demographical data and additional data on animal movement patterns, can later be used to create a spatially-explicit distribution model for American ginseng. 


\section{Literature Cited}

Anderson, R. C., J. S. Fralish, J. E. Armstrong, and P. K. Benjamin. 1993. The ecology and biology of Panax quiinquefolium L. (Araliaceae) in Illinois. American Midland Naturalist 129(2): 357-372.

Augspurger, C. K. 1984. Seedling survival of tropical tree species-interactions of dispersal distance, light-gaps, and pathogens. Ecology 65(6): 1705-1712.

Bohrer, G., R. Nathan, and S. Volis. 2005. Effects of long-distance dispersal for metapopulation survival and genetic structure at ecological time and spatial scales. Journal of Ecology 93: 1029-1040.

Cousens, R., C. Dytham, and R. Law. 2008. Dispersal in plants: A population perspective. Oxford University Press, Oxford, United Kingdom.

Cruse-Sanders, J. M. \& J. L. Hamrick. 2004. Spatial and genetic structure within populations of wild American ginseng (Panax quinquefolius L., Araliaceae). Journal of Heredity 95(4): 309-321.

Division of Management Authority. 2013. U.S. Exports of American ginseng (1992-2012). U.S. Fish and Wildlife Service, Department of Interior.

Elliot, L. 1978. Social behavior and foraging ecology of the Eastern chipmunk (Tamias striatus) in the Adirondack Mountains. Smithsonian Contributions to Zoology, Smithsonian Institution Press, Washington D.C.

Engler. R. \& A. Guisan. 2009. MigClim: Predicting plant distribution and dispersal in a changing climate. Diversity and Distribution 15: 590-601.

Fenner, M. (ed.) 2000. Seeds: The ecology of regeneration in plant communities, 2 edn. CAB International, Wallingford, UK. 
Furedi, M. A. and J. B. McGraw. 2004. White-tailed deer: dispersers or predators of American ginseng seeds? American Midland Naturalist. 152: 268-276.

Hulme P. E. 2002. Seed-Eaters: Seed Dispersal, Destruction and Demography In: Levey DJ, Silva WR, Galettie M (eds) Seed Dispersal and Frugivory: Ecology, Evolution and Conservation. CAB International Press, Oxfordshire, 257-273.

Izhaki, I. \& U. N. Safriel. 1989. Why are there so few exclusively frugivorous birds? Experiments on fruit digestibility. OIKOS 54: 23-32.

Johannsen, K. 2006. The Secret World of America's Most Valuable Plant. The University Press, Lexington, Kentucky, United States of America.

Lewis, W. H. and V. E. Zenger. 1982. Dynamics of American ginseng Panax quinquefolium (Araliaceae). American Journal of Botany 69(9): 1483-1490.

McGraw, J. B., S. M. Sanders, M. E. Van der Voort. 2003. Distribution and abundance of Hydrastis canadensis L. (Ranunculaceae) and Panax quinquefolius L. (Araliaceae) in the Central Appalachian Region. Journal of the Torrey Botanical Club 130:62-69.

McGraw J. B and M. A. Furedi. 2005. Deer browsing and population viability of a forest understory plant. Science $307:$ 920-922

McGraw, J. B., M. A. Furedi, K. Maiers, C. Carroll, G. Kauffman, A. Lubbers, J. Wolf, R. C. Anderson, M. R. Anderson, B. Wilcox, D. Drees, M. E. Van der Voort, M. A. Albrect, A. Nault, H. MacCulloch, and A. Gibbs. 2005. Berry Ripening and harvest season in wild American ginseng. Northeastern Naturalist, 12(2): 141-152.

McGraw, J. B., A. E. Lubbers, M. E. Van der Voort, E. H. Mooney, M. A. Furedi, S. Souther, J. B. Turner, J. Chandler. 2013. Ecology and conservation of ginseng (Panax quinquefolius) in a changing world. Annals of the New York Academy of Sciences 1286(1): 62-91. 
Pritts, K. D. 2010. Ginseng: How to find, grow, and use North America's forest gold, 2ed. Stackpole Books, Pennsylvania, United States.

Pearson, R. G. and T. P. Dawson. 2003. Predicting the impacts of climate change on the distribution of species: are bioclimate envelope models useful? Global Ecology \& Biogeography 12: 361-371.

Robbins, C. S. 2000. Comparative analysis of management regimes and medicinal plant trade monitoring mechanisms for American ginseng and goldenseal. Conservation Biology 14(5): $1422-1434$.

Stiles, E. W., 1980. Patterns of fruit presentation and seed dispersal in bird-disseminated woody plants in Eastern deciduous forest. The American Naturalist, 116(5): 670-688.

Souther, S. and J. B. McGraw. 2011. Local adaptation to temperature and its implications for species conservation in a changing climate. Conservation Biology 25(5)922-931.

Souther, S. and J. B. McGraw. in press. Synergistic effects of climate change and harvest on extinction risk of American ginseng. Ecological Applications.

Thuiller, W., C. Alber, M. B. Araújo, P. M. Berry, M. Cabeza, A. Guisan, T. Hickler, G. F. Midgley, J. Paterson, F. M Schurr, M. T. Sykes, and N. E. Zimmermann. 2008. Predicting global change impacts on plant species distributions: Future challenges. Perspectives in Plant Ecology, Evolution, and Systematics 9: 137-152.

Trakhtenbort, A., R. Nathan, G. Perry, and D. M. Richardson. 2005. The importance of longdistances dispersal in biodiversity conservation. Diversity and Distributions 11: 173-181.

Van der Voort, M. E.. 2005. An ecological and demographic study of American ginseng (Panax quinquefolius L.) in central Appalachia. Ph.D. dissertation, West Virginia University, Morgantown, West Virginia. 
Wolff, J. O. 1996. Fluctuations of mast-eating rodents are correlated with production of acorns. Journal of Mammalogy 77(3): 850-856 
Chapter 2: Songbird dispersal of American ginseng (Panax quinquefolius L.) 


\begin{abstract}
American ginseng (Panax quinquefolius L.) is an uncommon perennial understory herb found in eastern deciduous forest. The species is harvested for the international medicinal plant trade. While previous research has inferred that seed dispersal is limited, the production of bright red, fleshy berries suggests long-distance dispersal may be facilitated by songbirds. The objective of this study was to determine how songbirds interacted with ginseng and whether they dispersed or predated ginseng seeds. We used infrared, motion-activated cameras to observe animal-ginseng interactions in the field. To determine the disperser potential of songbirds observed visiting ginseng in the field, we conducted a captive feeding study at the Tennessee Aquarium. Thrushes removed berries from ginseng infructescences more frequently, compared to other potential dispersers, and regurgitated viable seeds $5-37$ minutes after ingestion in feeding trials. By dispersing ginseng seeds over intermediate to long distances, thrushes provide a mechanism for ginseng to improve the probability of persistence in the face of three main primary threats to populations: deer browse, harvest, and climate change.
\end{abstract}

Formatted for submission to the journal Écoscience 


\section{Introduction}

American ginseng (Panax quinquefolius L.) is a forest herb found throughout Appalachia, known for its medicinal properties (Johannsen, 2006). Annually, hundreds of thousands of wild ginseng roots are harvested and sold into the international medicinal plant trade (USFWS, 2012), generating millions of dollars in supplemental income for harvesters (Robbins, 2000). Concerns about overharvest of ginseng led to its listing on Appendix II of the Convention on International Trade in Endangered Species of Wild Fauna and Flora (CITES) in 1975, and resulted in monitoring the international export of American ginseng roots (Robbins, 2000).

In addition, American ginseng is a long-lived, perennial herb found in thousands of small populations throughout Appalachian forests that are characterized by a clustered spatial distribution of individuals within populations (McGraw $\underline{\text { et al. }}$, 2003; Cruse-Sanders \& Hamrick 2004a). Due to its economic importance, a life cycle similar to many other understory herbs, and its wide spatial distribution comprised of thousands of small populations, American ginseng has become a model species for investigating a plethora of demographic and conservation based questions. Extensive research has been conducted investigating the demography of American ginseng and how various environmental factors influence individual plant performance (reviewed in McGraw et al. , 2013). However, a critical aspect of ginseng demography that remains poorly understood is its dispersal (Cruse-Sanders \& Hamrick 2004a; Cruse-Sanders \& Hamrick 2004b; McGraw et al. , 2013).

Dispersal influences the spatial distribution, gene flow, and evolution of a species. Seed dispersal increases the distance between parent and offspring, thereby reducing competition and disease transmission between the parent and offspring, and among siblings, as well as decreasing 
other intraspecific interactions between individuals within a population (Augsperger, 1984). Dispersal reduces inbreeding with relatives, but in species such as ginseng that display Allee effects (Hackney \& McGraw, 2001), dispersal may also isolate individuals from potential mates, increasing the degree of selfing. Seed dispersal also facilitates the expansion of a population as well as the establishment of new populations (Howe \& Smallwood, 1982; Clark \& Clark, 1984; Clark et al. , 2007). Recent concerns over the potential for populations and species to shift distribution in response to changing climate have highlighted the need for a comprehensive investigation of plant dispersal mechanisms (e.g. Pearson \& Dawson, 2003; Thuiller $\underline{\underline{e t} \text { al. }}$, 2008; Engler \& Guisan, 2009; Souther \& McGraw 2011). Understanding dispersal mechanisms is therefore not only important for understanding the current distribution of ginseng populations, but also its future distributions.

To date, American ginseng seeds have been considered to be gravity dispersed (Lewis \& Zenger, 1982; Van der Voort, 2005). Gravity dispersal results in short distance dispersal events for plant species and is often combined with one or more other dispersal mechanisms (Vittoz \& Engler, 2007). American ginseng produces fleshy, red berries, suggesting animal-facilitated seed dispersal (Howe \& Smallwood, 1982; McGraw et al. , 2013). The best-documented ginsenganimal interaction is by white-tailed deer (Odocoileus virginianus). However, feeding trials showed that seeds were rendered inviable when berries are ingested (Furedi \& McGraw, 2004). Other ginseng seed-animal interactions have only been the subject of anecdotes, though phenology and morphological characteristics of ginseng berries suggest songbirds may facilitate ginseng dispersal (Pritts, 2010).

Green ginseng berries begin to form in mid-July and ripen to red throughout August and September (McGraw et al. , 2005). While some songbirds are frugivorous year-round, many 
migratory songbirds switch from an insectivorous diet to a frugivorous diet during the fall prior to migration, increasing the demand for fruits (Stiles, 1980; Izhaki \& Safriel, 1989). Additionally, songbirds are particularly attracted to fruits that have a strong contrast against foliage, resulting in a diet of fruits that are primarily purple, red, or black in color (Schmidt \& Schaefer, 2004; Iluz, 2011). Ginseng berries contain one to three seeds and can range from 3-10 $\mathrm{mm}$ in size, with seeds that are less than five millimeters. The ability of frugivorous bird species to ingest fruit has been shown to be limited by the width of the gape, particularly for species that gulp, or ingest, the whole fruit (Wheelwright, 1985; Piper, 1986; Jordano, 1987; Levey, 1987; Lambert, 1989). The small size of American ginseng seeds would theoretically allow it to be ingested by a majority of songbird species within its range (Meyer \& Whitmer, 1998). Furthermore, ginseng seeds have a hard exterior coat that may prevent damage to the embryo after being ingested and possibly pass through a bird's gizzard (Cousens et al. 2008).

The overall objective of this study was to investigate songbirds as potential seed dispersers of American ginseng. Specifically, we asked: (1) What is the frequency and "intimacy" of animal-ginseng interactions, particularly songbird interactions? (2) What proportion of berries is removed as the result of ginseng-animal interactions? (3) Is there a difference in the frequency and "intimacy" of avian-ginseng interactions compared to mammalian-ginseng interactions? (4) Of the avian interactions, what songbird species most frequently interact with ginseng? (5) Do songbirds that interact with ginseng defecate or regurgitate viable seeds? (6) How long do ginseng seeds stay within a songbird's digestive system?

\section{Methods}




\section{Field Investigation of Songbird-Ginseng Interactions}

In order to determine whether or not songbirds interact with American ginseng and how close their interactions are, Moultrie D40 infrared, motion-activated wildlife cameras were placed within six wild ginseng populations near Morgantown, West Virginia from 2007-2013 (Total populations/Year: 1/2007; 3/2009; 2/2010; 2/2011; 3/2012; 2/2013). One to three cameras were set up per site in mid-August, once berries began to ripen from green to red. Most often, cameras were removed once berries were absent from the infructescence or the plant had senesced. Wildlife cameras were positioned on $1.3 \mathrm{~m}$ tall, 5 x $10 \mathrm{~cm}$ camouflage-painted wooden stakes, at a distance of 1-2 m from a focal reproductive plant or cluster of reproductive plants within a population. For each instance that a camera was triggered by an infrared movement, the wildlife cameras were set to take three images. These three images were used to define a single potential disperser event. The cameras were also programmed to have a one minute delay between each of these events.

The images produced were cataloged and each potential disperser event was assigned a value that corresponded to the level of interaction a potential disperser had with the focal ginseng plant(s). Events were categorized based on a 0-5 scale, where 0 represented the lowest level of interaction, no apparent potential disperser within the image (but something triggered the camera), and 5 represented the highest level, with berries clearly removed by the potential disperser from the ginseng infructescence (Table 2.1). Only images where a portion of or all berries had ripened were used for calculations and analyses. Summary statistics included: (1) mean number of events per camera-day, (2) frequency of potential dispersers within a given level of interaction, (3) proportion of events with no visible potential disperser, (4) proportion of berries missing per plant after a level 4 or 5 interaction with a potential disperser, (5) total 
proportion of overall potential dispersers that were avian or mammalian, and (6) proportion of potential dispersers that were avian and mammalian per level of interaction. For those events containing a potential disperser, a loglikelihood analysis was performed using SAS JMP Statistical Software v11.0 (SAS Institute, Cary, North Carolina, USA) to determine whether avian potential dispersers more frequently had high-level interactions with ginseng compared to mammalian potential dispersers. For this analysis, the level of interaction was dependent on the category of potential disperser within an event (avian or mammalian). Additionally, given the types of avian potential dispersers observed within the images, a second loglikelihood analysis compared the level of interaction of thrush (Turdidae) species and non-thrush avian potential dispersers had with ginseng; where the level of interaction dependent on whether a species was a thrush species. 
Table 2.1. Levels of Interaction. Each event, made up of a series of three images per IRmotion activated occurrence, was assigned a quantitative value to represent the level of interaction a potential disperser (PD) had with American ginseng berries.

\begin{tabular}{|c|c|c|}
\hline & $\mathbf{0}$ & No PD is located within the photograph. \\
\hline \multirow{3}{*}{ 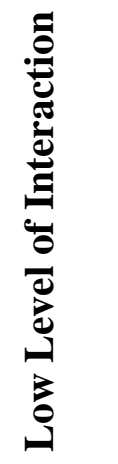 } & 1 & $\begin{array}{l}\text { The PD is in photograph and not under the canopy }{ }^{1} \text { of the ginseng plant for two or more } \\
\text { images. }\end{array}$ \\
\hline & 2 & $\begin{array}{l}\text { The } \mathrm{PD} \text { is under the canopy }{ }^{1} \text { of the ginseng plant for at least } 2 / 3 \text { images, but it is not } \\
\text { foraging. }\end{array}$ \\
\hline & 3 & $\begin{array}{l}\text { The PD is under the canopy of the plant in question for at least } 2 / 3 \text { images and is } \\
\text { foraging }^{2} \text {. }\end{array}$ \\
\hline \multirow{2}{*}{ 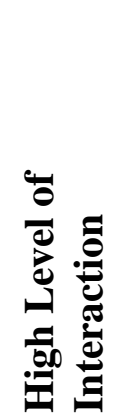 } & 4 & $\begin{array}{l}\text { The PD has touched the infructescence. } \\
\text { A berry goes missing between two events, with at one of the events having an identifiable } \\
\text { PD. }\end{array}$ \\
\hline & 5 & $\begin{array}{l}\text { There is a berry within the PD's possession. } \\
\text { Within the three image sequence of an event, a berry has been removed from the } \\
\text { infructescence. }\end{array}$ \\
\hline
\end{tabular}

${ }^{1}$ under canopy: the potential disperser appears below the leaves of the focal ginseng plant ${ }^{2}$ foraging: the potential disperser has its nose or beak to the ground below the leaves of the focal ginseng plant 


\section{Investigation of Thrushes as Potential Dispersers}

Based on the field observation of thrushes as one of the most frequent potential avian dispersers, feeding trials were conducted with four captive thrushes at the Tennessee Aquarium from September 5-8, 2013. Over the course of 2.5 days, ginseng berries were fed ad libitum to a hermit thrush (atharus guttatus), Swainson's thrush (Catharus ustulatus), veery (atharus fuscescens), and wood thrush (Hylocichla mustelina). Due to renovations to their normal exhibit, the hermit thrush, Swainson's thrush, and veery were maintained in a cage environment (47.5 $\mathrm{cm}$ x $47.5 \mathrm{~cm} \times 90 \mathrm{~cm}$ ), and had been living there for four weeks. While the hermit thrush was placed in a cage by itself, the Swainson's thrush and veery were caged together due to space limitations. Additionally, due to space limitations, the wood thrush could not also be caged and feeding trials for this species were conducted within its normal delta country exhibit (ca. 1200 $\mathrm{m}^{2}$ ), which included vegetation as well as other bird species.

Berry production is low in natural populations, so ginseng berries for feeding trials were obtained from a ginseng cultivator using "woods grown" growth methods (under natural tree canopy). Berries were collected directly from plants two days prior to the feeding trials and were stored at $4{ }^{\circ} \mathrm{C}$. Ginseng berries were offered within the normal feeding time (8AM- $5 \mathrm{PM}$ ). During the first day and for the morning of the second day, berries were offered simultaneously with normal food items (mealworms, sunflower seeds, etc.) in order to minimize stress to the birds in case they rejected the fruit. Berries were offered as the sole food item for the remaining trials during the afternoon of the second day and the morning of the third day, after birds had been observed ingesting the berries.

Within the exhibit that held the wood thrush, at least two observers were present to record wood thrush feeding behavior, given that the bird still had free movement within the exhibit and 
other species that could potentially eat the berries were present. Video cameras were used to record the behavior of the caged birds. Primary observations were made regarding the digestive behaviors (whether seeds were defecated or regurgitated) of the thrushes and the amount of time between ingestion and an exhibited digestive behavior. Additional observations were made regarding the total number of berries that were eaten by each bird, the proportion of one-seeded and two-seeded berries eaten, and, in the wood thrush exhibit, the number of other avian species that interacted with and the type of interactions they had with the ginseng berries. Recovered seeds that had been ingested were tested for embryo viability using a $0.1 \%$ tetrazolium chloride solution (Baskin \& Baskin, 1998).

\section{Results}

\section{Field Investigation of Songbird-Ginseng Interactions}

Of the original cameras deployed, image collection for three cameras (1:2009, 1:2010; 1:2013) ended prematurely due to battery drain or a camera malfunction and therefore images of potential dispersers were not collected after berries had ripened. Additionally, a total of eight camera trials were not able to be included in analyses because memory cards were stolen (4:2009; 3: 2012; 1; 2013), often because of illegal harvest of the focal plant(s). In total, 15 wildlife cameras were used from 2007-2013, resulting in 241 camera-days and a total of 925 camera-triggered events (2,775 total images). Wildlife cameras were triggered $3.9+/-0.3$ (mean +/-SE) times per camera-day, with a range of 0-35 triggered events per camera-day. Of the total 925 triggered events, 647 events had no potential disperser (Level 0 Interaction; Table 2.1), 230 had mammalian potential dispersers, and 48 had avian potential dispersers. 
A majority $(83.1 \%)$ of the events for both avian and mammalian potential dispersers were categorized as a Level 1 interaction. Of the interaction levels that involved direct interaction with a ginseng infructescence and berries (Levels 4 and 5), mammals were categorized most frequently as Level 4 interaction while birds were categorized most frequently as Level 5 interactions (Table 2.2). On average, 2 berries were missing from an infructescence following a Level 4 or 5 Interaction by a potential disperser for every 7 berries available (+/- 0.085$)$. Six berries was the maximum amount of berries missing from focal infructescences as the result of or following Level 4 and 5 avian interactions (Table 2.3); whereas, one berry was the maximum number of berries missing or removed from focal infructescences following a Level 4 and 5 mammalian interaction (Table 2.3).

To have enough replication to statistically compare mammalian and avian dispersers, the levels of interaction were simplified. Levels 1-3 were combined into a single category we term 'Low Level', because these included behaviors that did not involve direct interaction with the ginseng infructescence and were therefore least likely to result in a dispersal event. Levels 4 and 
1 Table 2.2. The total number of events for each mammalian and avian species per levels of interaction.

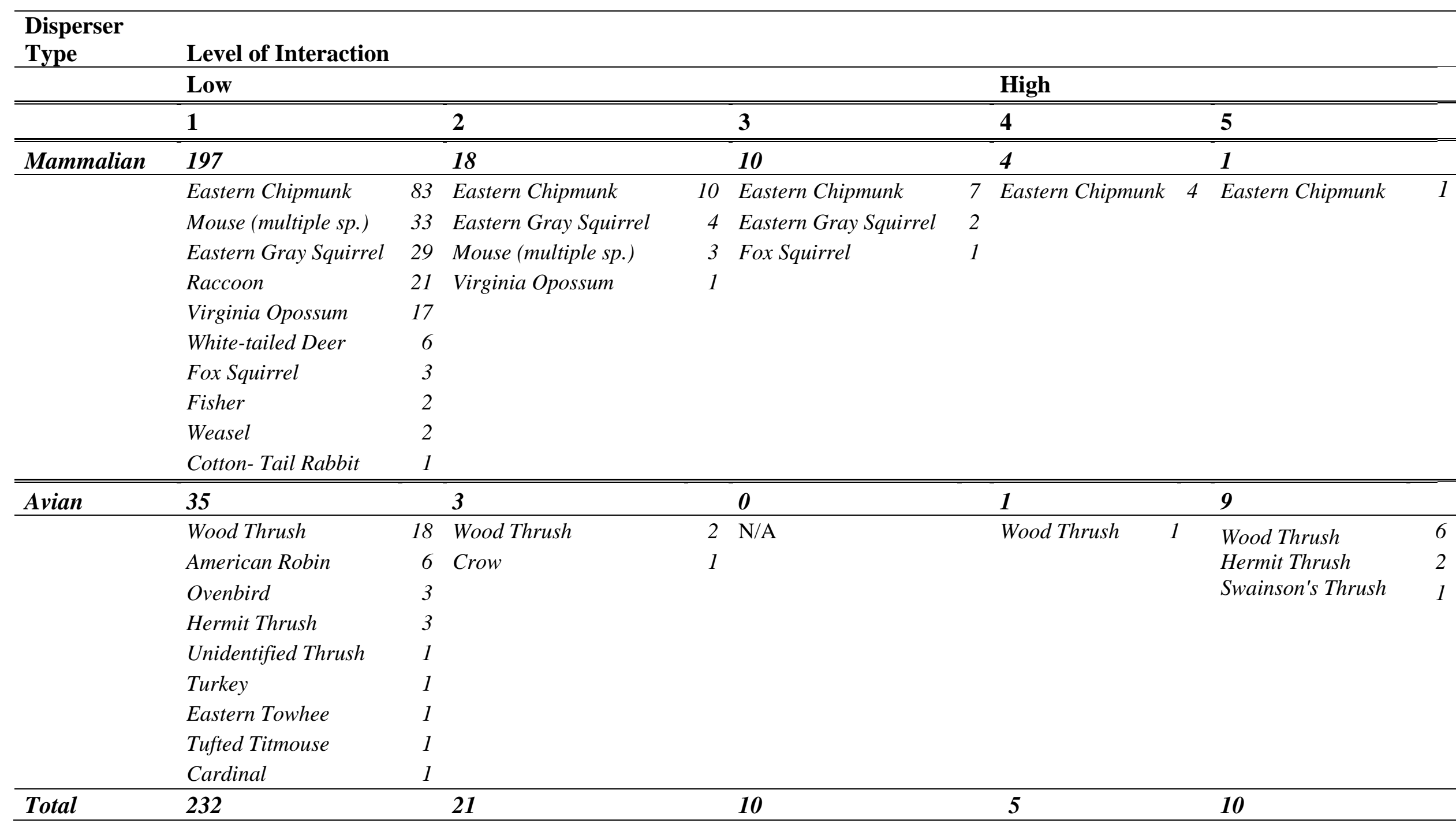


Table 2.3. The total number of berries removed per camera location as a direct result or following a Level 4 or 5 Interaction with a potential disperser and the species responsible for the berry removal at each camera location.

\begin{tabular}{|c|c|c|c|}
\hline Camera ID & $\begin{array}{l}\text { Berries } \\
\text { Removed } \\
\end{array}$ & $\begin{array}{l}\text { Berry } \\
\text { Total } \\
\end{array}$ & Interacting Species \\
\hline FCF1 & 6 & 6 & Wood Thrush \\
\hline TPW1 & 4 & 8 & Wood Thrush, Hermit Thrush \\
\hline TPG & 2 & 3 & Swainson's Thrush, Eastern Chipmunk \\
\hline FCF3 & 2 & 4 & Wood Thrush \\
\hline FCF2 & 1 & 3 & Hermit Thrush \\
\hline AF2 & 1 & 3 & Eastern Chipmunk \\
\hline AF1 & 1 & 2 & Eastern Chipmunk \\
\hline WL2 & 1 & 8 & Eastern Chipmunk \\
\hline P41 & 0 & 3 & N/A \\
\hline TP1 & 0 & 10 & N/A \\
\hline TPR2 & 0 & 4 & N/A \\
\hline TPW2 & 0 & 5 & N/A \\
\hline TPRC & 0 & 2 & $N / A$ \\
\hline WL1 & 0 & 3 & $N / A$ \\
\hline TPR1 & N/A & N/A & $N / A$ \\
\hline
\end{tabular}


5 were combined into a category we refer to as 'High Level' because they included behaviors involving direct interaction with the ginseng infructescence and were most likely to result in a dispersal event. Mammalian and avian dispersers were significantly different in the proportion of Low and High Level of interactions with ginseng berries (Figure 2.1; likelihood ratio $\left.\chi^{2}=19.88, \mathrm{p}<0.0001\right)$. While mammalian potential dispersers most frequently triggered the wildlife cameras, avian potential dispersers were captured most frequently interacting directly with ginseng berries (Figure 2.1).

Squirrel species (Family: Sciuridae), accounted for the $60.8 \%$ of the 230 mammalian potential dispersal events. Eastern chipmunks (Tamias striatus) were the most frequent potential dispersers ( $\mathrm{n}=104)$, followed by mice (Peromyscus $s p$. ., Family: Cricetidae) $(\mathrm{n}=36)$ and Eastern gray squirrels ( $\underline{\text { Sciurus carolinensis })}(\mathrm{n}=35)$. Of the mammalian potential dispersers, only chipmunks interacted with ginseng berries at the High Level of interaction (Figure 2.2), but foraging behavior below focal ginseng plants (Level 3 interaction) was observed among chipmunks and squirrels (Table 2.2).

Of the avian potential dispersers, thrush species (Family: Turdidae) accounted for $81.3 \%$ of the 49 avian events. The most common avian potential dispersers were wood thrushes ( $n=27)$, followed by American robins (Turdus migratorius) $(\mathrm{n}=6)$ and hermit thrushes $(\mathrm{n}=5)($ Table 2). Using the Low and High levels of interaction, thrush species were found to differentially interact with ginseng relative to other avian potential dispersers (likelihood ratio $\chi^{2}=4.140 ; \mathrm{p}=0.0419$ ), and were found to most frequently interact with the infructescence and berries (Figure 2.3). The three thrush species that were found to interact with the infructescence and ginseng berries were wood thrushes $(n=7)$, hermit thrushes $(n=2)$, and a Swainson's thrush $(n=1)$ (Figure 2.2). 


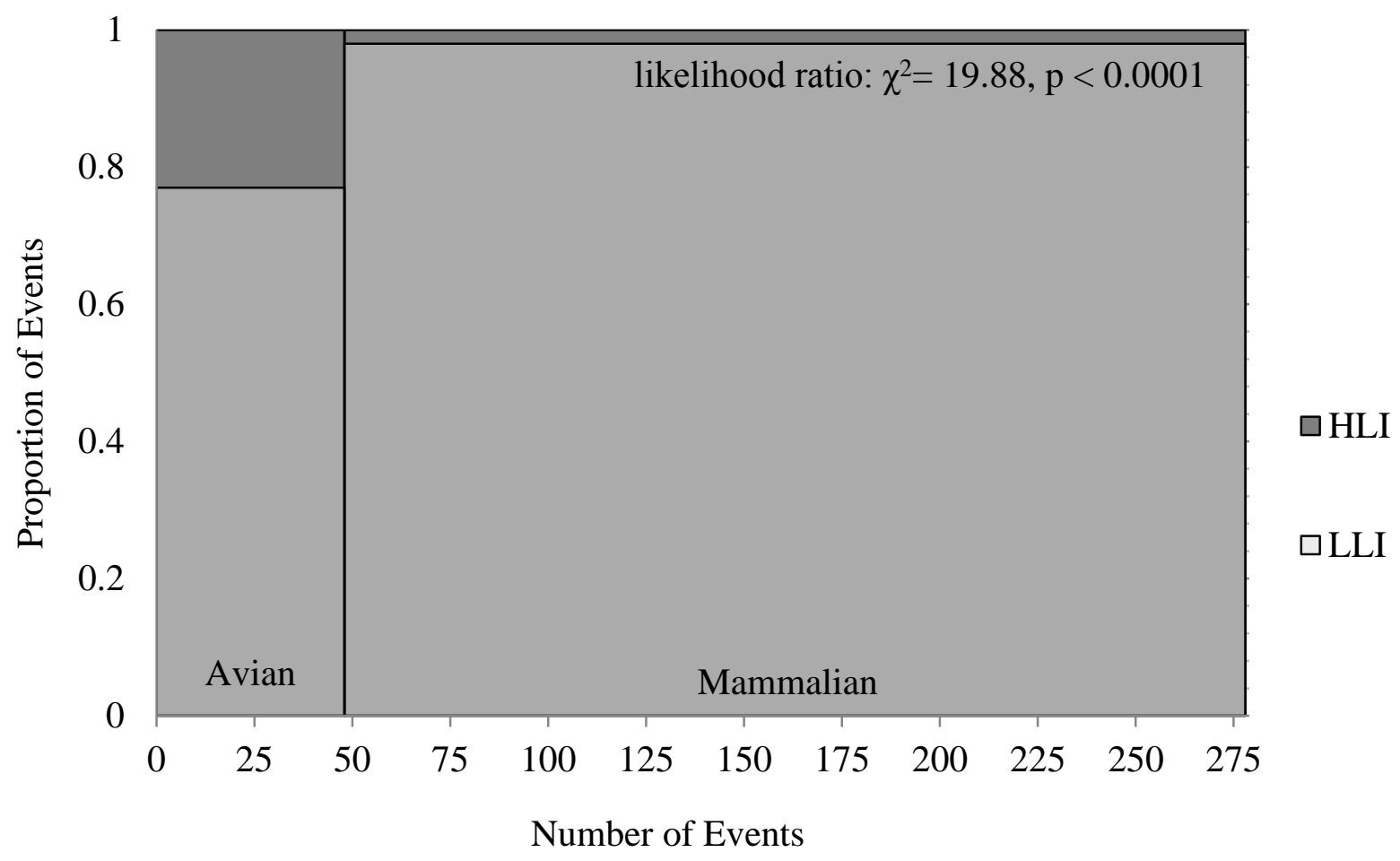

Figure 2.1. Partitioning of avian and mammalian potential disperser events based on categories that would least likely result in a dispersal event (LLI: Low Level of Interaction) and most likely result in a dispersal event (HLI: High Level of Interaction). 


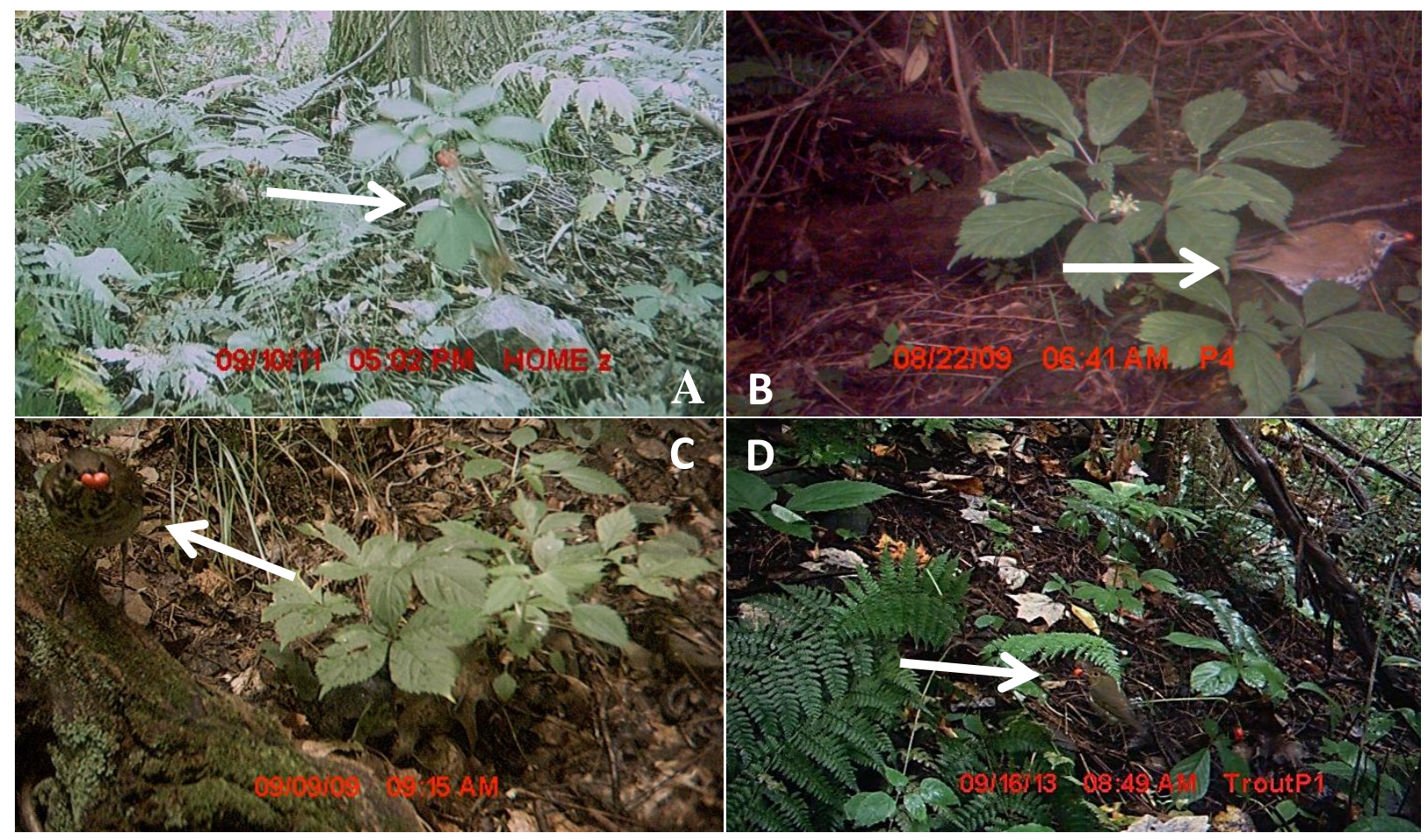

Figure 2.2. A. Image of an Eastern chipmunk demonstrating High Level Interaction behavior by touching the ginseng infructescence, B. Image of a wood thrush demonstrating High Level Interaction behavior with a berry in its beak. C. Image of a hermit thrush demonstrating High Level Interaction behavior with a berry in its beak. D. Image of a Swainson's thrush demonstrating High Level Interaction behavior with a berry in its beak. 


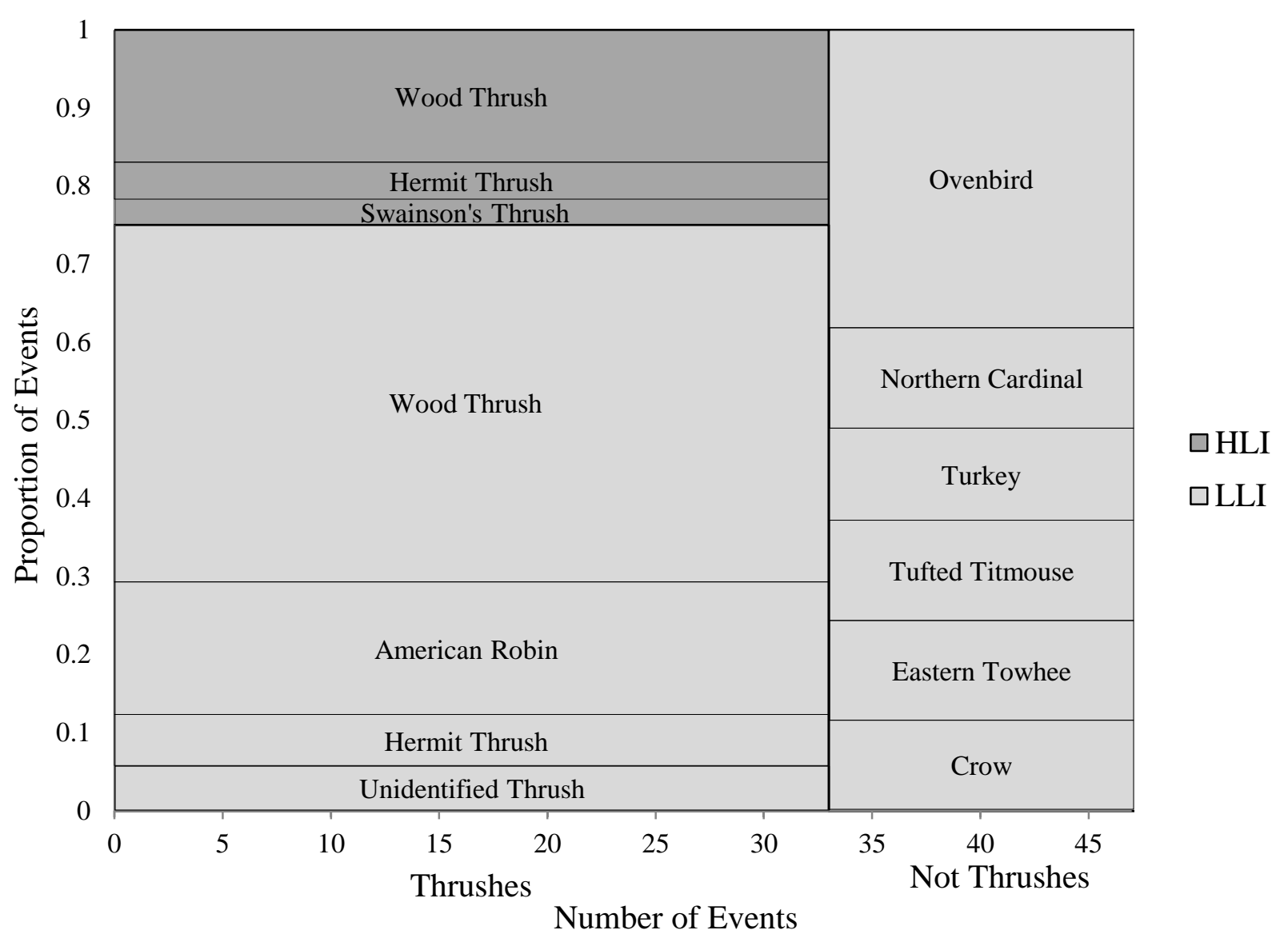

Figure 2.3. Partitioning of thrush and non-thrush potential disperser events based on categories that would least likely result in a dispersal event (LLI: Low Level of Interaction) and most likely result in a dispersal event (HLI: High Level of Interaction) with the proportion of species within each category. 


\section{Investigation of Thrushes as Potential Dispersers}

Over the course of two and a half days, a total of 80 berries were offered within the wood thrush exhibit, 80 berries within the hermit thrush cage, and 61 berries to the veery and Swainson's thrush. All thrushes ingested at least one berry, with the wood thrush ingesting the highest number of berries over the course of two and a half days. Ingested seeds were regurgitated by all thrushes, with an average time of $15 \min 55 \mathrm{sec}+/-3 \min 44 \sec (\mathrm{N}=9)$ between ingestion and regurgitation. The wood thrush ingested a total of twelve berries. Seven wood thrush regurgitation events were observed, with five events occurring after a specific and isolated feeding event. Of these isolated regurgitation events, a mean time of $23 \mathrm{~min} 12 \mathrm{sec}+/-3$ min $35 \mathrm{sec}$, with a minimum time of $15 \mathrm{~min}$ and a maximum of $37 \mathrm{~min}$, between ingestion and regurgitation was observed. The veery ingested only two berries, both one-seeded, and had a mean time of $7 \mathrm{~min} 15 \mathrm{sec}+/-2 \mathrm{~min} 43 \mathrm{sec}$ between ingestion and regurgitation. The Swainson's thrush ingested a single, two seeded berry during the study and regurgitated the first seed $5 \mathrm{~min} 33 \mathrm{sec}$ after ingestion and the second seed $7 \mathrm{~min} 14 \mathrm{sec}$ after ingestion. The hermit thrush did eat one berry over the course of the study, but the time until regurgitation was not recorded. However, given that the seed of the missing berry was recovered, clean of pulp and without feces, it was determined that a regurgitation event had occurred. A total of eight seeds that had been regurgitated were recovered (wood thrush: 3; Swainson's and veery: 3; hermit thrush: 1). All recovered seeds were found to be viable by the tetrazolium test after regurgitation.

Other bird species within the Delta exhibit at the Chattanooga Aquarium ingested ginseng berries. Of the 80 berries offered within the exhibit, cardinals (Cardinalis cardinalis) ate 47 berries, a summer tanager ( $\underline{\text { iranga rubra }}$ ) ate four berries, and a cedar waxwing (

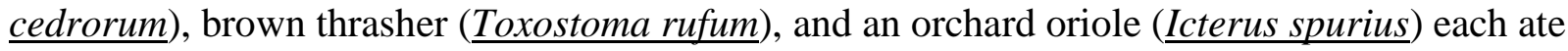


one berry. While most of the other species that ate berries were not observed for their digestive behaviors, the cardinals predated the ginseng seed by removing the pulp and seed coat from the ginseng seed and ingesting the unprotected interior of the seed containing the plant embryo.

\section{Discussion}

Previous work with infrared, motion-activated wildlife cameras has shown that there is uncertainty as to what triggers an event not only between different models of cameras but also between individual cameras of the same model when detecting wildlife events (Swann $\underline{\text { et al. }}$, 2004; Hughson et al. , 2010). While we tried to decrease this uncertainty by mounting cameras in a systematic fashion, a number of events triggered the cameras during this study but did not have a visible potential disperser within the images. Three explanations for these uninformative images are possible: (1) false triggers in which an event is triggered by something other than an animal, (2) an event is triggered by a potential disperser that is out of frame or is hidden at the time of shutter release and therefore is missing in the image (Swann et al. , 2004), or (3) very effective camouflage resulting in the observer falsely concluding no animal was present. False triggers may occur due to environmental factors, such as the wind moving either vegetation or the camera mount (Swann et al. , 2004). This cause would not bias the potential disperser information obtained by the camera. The latter two causes could bias the set of images obtained in favor of slower moving, larger, or more visible animals. By setting the cameras to take three images per event, these errors can be reduced in frequency at the analysis stage by carefully toggling between the images to detect movement within the event.

While an unknown bias in the frequency of capture of different species may have occurred, these cameras nevertheless provide a simple and sophisticated methodology for 
observing plant-animal interactions that would be impossible by direct observation. By using wildlife cameras, a total of 5,784 hours (241 camera-days) of observation time were logged, resulting in sequences of images that were then analyzed carefully in a lab setting. Additionally, wildlife cameras are less intrusive then human observers, which can stress wildlife and decrease the probability of an animal-ginseng interaction (Cutler \& Swann, 1999).

Using wildlife cameras to observe animal interactions with American ginseng, we have determined that animal-ginseng interactions are variable in intensity and not as rare as previously thought. Five percent of all events with potential dispersers were categorized as High Level interactions and did not occur at every camera location, but resulted in removal of all of the berries from an infructescence at one of the camera locations (Table 2.3). Of the potential dispersers observed, thrushes, particularly wood thrushes, most frequently removed berries directly from the plants, but chipmunks also had High Level interactions with ginseng infructescences. Additionally, interactions categorized as Level 3 in the Low Level Interactions demonstrate foraging below the ginseng plants and these events may result in secondary dispersal by small mammals (Vander Wall, Kuhn, \& Gworek, 2005; Vander Wall \& Beck, 2012). High Level thrush-ginseng interactions are most frequently represented in the data, making thrushes the most likely candidate for animal dispersal events beyond the distances recorded for dispersal by gravity (Van der Voort, 2005).

Wood thrushes may have been the most common avian species to trigger an event because their breeding habitat range is nearly identical to that of American ginseng (Sibley 2000). Hermit thrushes and Swainson's thrushes, the other two thrush species to have High Level interactions, have a more northern breeding range and may have been interacting with ginseng while en route to wintering sites (Cherry, 1985; Kwit et al., 2004). Additionally, the 
veery, a species that was not observed on camera but was fed during the captive feeding trials, may not have been detected during field observations because their breeding range also only overlaps the northern distribution of American ginseng (Bayly et al. , 2012). But they too could ingest ginseng at stopover sites en route to their wintering grounds.

Our feeding studies demonstrated that after berries were ingested by a thrush species, viable ginseng seeds were regurgitated. Meyer and Witmer (1998) demonstrated that the germination of similar seeds, with similar germination requirements (Spicebush: $\underline{\text { Lindera }}$

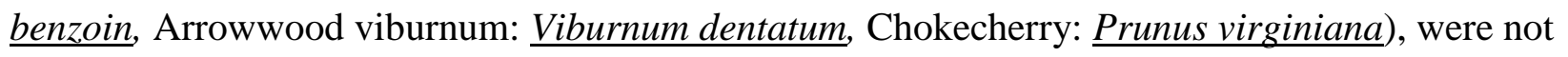
affected by thrush regurgitation when grown in a controlled greenhouse setting. Given that ginseng has a high natural germination rate in the field (McGraw et al. , 2013), if germination is not hindered by thrush regurgitation, there is a high probability that seeds dispersed by thrushes will germinate and persist when dispersed to a suitable site.

The distances traveled between an ingestion and regurgitation site are expected to be shorter than distances traveled between an ingestion and defecation site, given the amount of time the seeds stay within a bird's digestive system (e.g. Meyer \& Witmer, 1998; Clark et al. 2005; Uriate et al. , 2011). On average, ginseng seeds were regurgitated after 16 minutes, which is consistent with other recorded thrush regurgitation times for seeds of similar sizes (Spicebush: Lindera benzoin, Arrowwood viburnum: Viburnum dentatum, Chokecherry: Prunus virginiana; Meyer and Witmer, 1998).

Contrasting behaviors exhibited by adults and juveniles during the seed dispersal season may result in different sets of dispersal distances for ingested ginseng seeds. Post breeding adult thrushes relocate 550 - 7,000 m from nesting sites to new molting sites (Vega Rivera et al. 1999). While these distances may not be traversed within one flight, they do tend to occur late 
July- early August and can overlap with the early ripening of ginseng berries (Rivera et al. 1998b; McGraw et al. , 2005). However, once adult thrushes begin their pre-migration molt, which is centered on the ginseng seed ripening period, their ability to fly is drastically reduced. This causes them to become secretive and find areas of dense forest cover and high food abundance in order to avoid predator detection (Vega Rivera et al., $1998 \mathrm{~b}$ ). During their molt, adult thrush mobility decreases by almost 50 percent compared to movement during breeding season (Vega Rivera et al., 1999); suggesting that adult thrushes will most likely move seeds less than $100 \mathrm{~m}$ between an ingestion and regurgitation site. Smith et al. (2004) observed a 70 percent probability that a hermit thrush will disperse a seed less than $100 \mathrm{~m}$ from the ingestion site over a 45 min time period during the winter season.

Juvenile thrushes, however, undergo a pre-basic molt prior to migration and spend time searching for optimal foraging sites and making exploratory movements (Vega Rivera $\underline{\text { et al. }}$, 1998a). After leaving the natal site, young thrushes will travel $150 \mathrm{~m}$, on average, to a dispersal site and will travel to as many as four different dispersal sites before their migration (Vega Rivera et al. , 1998a). Within these dispersal sites, juveniles moved approximately $100 \mathrm{~m}$ between consecutive locations and occasionally make exploratory movements greater than 300 $\mathrm{m}$ from the dispersal site (Vega Rivera et al., $1998 \mathrm{a}$ ). The larger range of mobility of juvenile thrushes provides an opportunity for rapid seed dispersal beyond $100 \mathrm{~m}$.

While most demographic models for plants assume random disperser movement, movement is most often the result of nonrandom behaviors (Schupp et al. , 2002). American ginseng is a species that was once abundant throughout Appalachian forest, but is now located in thousands of small populations with a clustered spatial distribution (Cruse-Sanders \& Hamrick, 2004a; McGraw et al. , 2013). While seed dispersal has been previously considered to be 
primarily via gravity, and therefore limited, our findings demonstrate that longer-distance dispersal events by thrushes are not rare. However, given that High Level thrush-ginseng interactions varied from frequent to absent, variation in habitat suitability for post breeding thrushes (Ozinga et al., 2004; Russo et al. 2006) will determine the frequency of such dispersal events.

Thrush populations have been declining in North America since the late 1960s due to habitat loss, fragmentation, and degradation, e.g. acid rain and brown-headed cowbird parasitism (Trine, 1998; Hames et al., 2002; Betts $\underline{\text { et al. }}$, 2010). American ginseng's broad niche may allow it to persist in sites where thrush populations are low or nonexistent. Populations in these sites would likely be confined to smaller areas, however, and would tend to be found in one or a few isolated patches rather than many dispersed clusters (Cruse-Sanders \& Hamrick, 2004a). However, ginseng growing in habitats that provide an abundance of food resources and protective cover would be more likely to have frequent interactions with thrushes and a greater probability for dispersal beyond 2 meters as well as long distance dispersal events in areas with a higher number of juvenile thrushes. Dispersal across the landscape by thrushes could produce not only many new subpopulations within a population, but also establish new populations across the landscape.

With thrushes now known to be primary seed dispersers, the recovery and conservation of thrush and ginseng populations in North America are connected. Ginseng provides a source of food for thrushes prior to migration and thrush dispersal of ginseng seeds in turn could improve ginseng's resilience in the face of the three most important factors shown to be causing population decline: deer browse, harvest, and climate change (McGraw et al., 2013). Thrush dispersal provides opportunity for ginseng to be dispersed away from areas with heavy deer 
traffic and areas of intense foraging, which is important because deer are seed predators (Furedi \& McGraw 2004) in addition to having negative effects as herbivores (McGraw \& Furedi 2005). During the fall thrushes are more likely to be found in areas of dense forest cover (Vega Rivera et al.. 1998b) and deer have been shown to less frequently browse ginseng in areas $>2 \mathrm{~m}$ away from deer paths and areas with denser shrub cover (Furedi 2004). Similarly, by providing the opportunity for the establishment of new populations, thrush dispersal also provides a way of escaping harvest. Harvesters return year after year to the same ginseng populations (McGraw $\underline{e t}$ al., 2010), so dispersal and establishment of new populations in areas where ginseng no longer exists could mitigate the effect of harvest on ginseng metapopulations. Furthermore, the discovery of thrushes as a primary disperser provides the greatest opportunity for ginseng to persist the face of climate change effects. Longer dispersal movements via thrushes would provide a greater opportunity for gene flow between locally-adapted populations (Souther \& McGraw 2011, Souther \& McGraw, in press), which may in turn enhance the ability of populations to persist in the face of climate change. Additionally, longer distance dispersal also provides the opportunity for new populations to establish in northern or higher elevation sites with similar microclimates to which they are adapted.

\section{Acknowledgments}

We would like to thank J. Chandler, M. Elza, and J. Turner for their help with camera set up, image collection, aquarium observations, and their feedback on the early version of this article. We thank the Tennessee Aquarium for the use of their facilities and care of the birds, in particular A. George and K. Calhoon for all of their assistance. Financial support was received from National Science Foundation Long Term Research in Environmental Biology Grant (NSF 
grant DEB-0613611 and DEB-1118702 to JBM).

\section{Literature Cited}

American Ornithologists' Union, 2012. The code of nomenclature and check-list of North American birds adopted by the American ornithologists' union: being the report of the committee of the union on classification and nomenclature. Forgotten Books, New York.

Augspurger, C. K., 1984. Seedling survival of tropical tree species-interactions of dispersal distance, light-gaps, and pathogens. Ecology, 65(6): 1705-1712.

Baskin, C. C. \& J. M. Baskin, 2000. Seeds: Ecology, Biogeography, and Evolution of Dormancy and Germination. Academic Press, San Diego, California.

Bayly, N. J., C. Gómez, K. A. Hobson, A. M. González, \& K. V. Rosenberg, 2012. Fall migration of the veery (Catharus fuscenscens) in northern Colombia: determining the energetic importance of a stopover site. The Auk, 129(3):449-459.

Betts, M. G., J. C. Hagar, J. W. Rivers, J. D. Alexander, K. McGarigal, \& B. C. McComb, 2010. Thresholds in forest bird occurrence as a function of the amount of early-seral broadleaf forest at landscape scales. Ecological Applications, 20(8): 2116-2130.

Cain, M. L., B. G. Milligan, \& A. E. Strand, 2000. Long-distance seed dispersal in plant populations. American Journal of Botany, 87(9): 1217-1227.

Cherry, J. D., 1985. Early autumn movements and prebasic molt of Swainson's thrush. The Wilson Bulletin, 97(3): 368-370.

Clark, C. J., J. R. Poulsen, B. M. Bolker, E. F. Connor, \& V. T. Parker, 2005. Comparative seed shadows, of bird-, monkey-, and wind-dispersed trees. Ecology, 86(10): 2685-2694

Clark, C. J., J. R. Poulsen, D.J. Levey, \& C. W. Osenbuerg, 2007. Are plant populations seed 
limited? A critique and meta-analysis of seed addition experiments. American Naturalist, 170: $128-142$.

Clark, D. \& D. Clark, 1984. Spacing dynamics of a tropical rainforest tree: Evaluation of the Janzen-Connell model. American Naturalist, 124: 796-788.

Cousens, R., C. Dytham, \& R. Law, 2008. Dispersal in plants: A population perspective. Oxford University Press, Oxford.

Cruse-Sanders, J. M. \& J. L. Hamrick, 2004a. Spatial and genetic structure within populations of wild American ginseng (Panax quinquefolius L., Araliaceae). Journal of Heredity, 95(4): 309-321.

Cruse-Sanders, J. M. \& J. L. Hamrick, 2004b. Genetic diversity in harvested and protected populations of wild American ginseng, Panax quinquefolius L. (Araliaceae). American Journal of Botany, 91(4): 540-548.

Cutler, T. L. \& D. E. Swann, 1999. Using remote photography in wildlife ecology: A review. Wildlife Society Bulletin, 27(3): 571-581.

Division of Management Authority, 2012. U.S. exports of American ginseng 1992-2011. U.S. Fish and Wildlife Service Department of the Interior, United States of America.

Engler. R. \& A. Guisan, 2009. MigClim: Predicting plant distribution and dispersal in a changing climate. Diversity and Distribution, 15: 590-601.

Furedi, M. A, 2004. Effects of herbivory by white-tailed deer (Odocoileus virginianus Zimm.) on the population ecology and conservation biology of American ginseng (Panax quinqufolius L.). Ph. D. Dissertation, West Virginia University, Morgantown, WV.

Furedi, M. A. \& J. B. McGraw, 2004. White-tailed deer: dispersers or predators of American ginseng seeds? American Naturalist, 152: 268-276. 
Grubbs, H. J. \& M. A. Case, 2004. Allozyme variation in American ginseng ( $\underline{\text { Panax }}$ quinquefolius L.): Variation, breeding system, and implications for current conservation practice. Conservation Genetics, 5: 13-23.

Hackney, E. \& J. B. McGraw, 2001. Experimental demonstration of an Allee effect in American ginseng. Conservation Biology 15(1): 129 - 136.

Hames, R. S., K. V. Rosenburg, J. D. Lowe, S. E. Barker, \& A. A. Dhondt, 2002. Adverse effects of acid rain on the distribution of the wood thrush Hylocichla mustelina in North America. Proceedings of the National Academy of Sciences, 99(17): 11235-11240.

Howe, H. F. \& J. Smallwood, 1982. Ecology of seed dispersal. Annual Review of Ecology and Systematics, 13: 201-228.

Hughson, D.L., N.W. Darby, \& J.D. Dungan, 2010. Comparison of motion-activated cameras for wildlife investigations. California Fish and Game, 96(2): 101-109.

Iluz, D., 2011. Zoochory: The dispersal of plants by animals. Pages 201-214 in J. Seck, Z. Dubinsky (eds). All Flesh is Grass: Plant-Animal Interrelationships. Springer Dordrecht Heidelberg, London, New York.

Izhaki, I. \& U. N. Safriel, 1989. Why are there so few exclusively frugivorous birds? Experiments on fruit digestibility. OIKOS, 54: 23-32.

Johannsen, K., 2006. Ginseng Dreams: The Secret World of America's Most Valuable Plant. The University Press of Kentucky, Kentucky.

Jordano, P., 1987. Avian fruit removal- effects of fruit variation, crop size, and insect damage. Ecology, 68(6): 1711-1723.

Kartez, J. T., 1994. A synonymized checklist of the vascular flora of the United States, Canada, and Greenland, $2^{\text {nd }}$ edition. Timber Press, Portland, Oregon. 
Kwit, C., D. J. Levey, C. H. Greenberg, S. F. Pearson, J. P. McCarty, S. Sargent, \& R. L. Mumme, 2004. Fruit abundance and local distribution of wintering hermit thrushes (Cartharus guttatus) and yellow-rumped warblers (Dendroica coronate) in South Carolina. The Auk, 121(1): 46-57.

Lambert, F. R., 1989. Pigeons as seed predators and dispersers of figs in Malaysian lowland forest. Ibis, 131: 521-527.

Levey, D. J., 1987. Seed Size and fruit-handling techniques of avian frugivores. American Naturalist. 129(4): 471-485.

Lewis, W. H. \& V. E. Zenger, 1982. Dynamics of American ginseng Panax quinquefolium (Araliaceae). American Journal of Botany, 69(9): 1483-1490.

McGraw, J. B., S. M. Sanders, \& M. E. Van der Voort, 2003. Distribution and abundance of $\underline{\text { Hydrastis canadensis }}$ L. (Ranunculaceae) and Panax quinquefolius L. (Araliaceae) in central Appalachian region. Journal of the Torrey Botanical Society, 130(2): 62-69.

McGraw, J. B., M. A. Furedi, K. Maiers, C. Carroll, G. Kauffman, A. Lubbers, J. Wolf, R. C. Anderson, M. R. Anderson, B. Wilcox, D. Drees, M. E. Van der Voort, M. A. Albrecht, A. Nault, H. MacCulloch, \& A. Gibbs, 2005. Berry Ripening and harvest season in wild American ginseng. Northeastern Naturalist, 12(2): 141-152.

McGraw, J. B. \& M. A Furedi, 2005. Deer browsing and population viability of a forest understory plant. Science, 307: 920-922.

McGraw, J. B., S. Souther, \& A. E. Lubbers, 2010. Rates of harvest and compliance with regulations in natural populations of American ginseng (Panax quinquefolius L.). Natural Areas Journal, 30(2): 202-210.

McGraw, J. B., A. E. Lubbers, M. Van der Voort, E. H. Mooney, M. A. Furedi, S. Souther, J. B. 
Turner, \& J. Chandler, 2013. Ecology and conservation of ginseng (Panax quinquefolius) in a changing world. Annals of the New York Academy of Sciences, 1286(1): 62-91.

Meyer, G. A. \& M. C. Witmer, 1998. Influence of seed processing by frugivorous birds on germination success of three North American shrubs. American Midland Naturalist, 140: 129-139.

Ozinga, W. A., R. M. Bekker., J. H. J. Schaminée, J. M. van Groenendael, 2004. Dispersal potential in plant communities depends on environmental conditions. Journal of Ecology, 92(5): 767-777.

Pearson, R. G. \& T. P. Dawson, 2003. Predicting the impacts of climate change on the distribution of species: are bioclimate envelope models useful? Global Ecology \& Biogeography, 12: 361-371.

Piper, J. K., 1986. Effects of habitat and size of fruit display on removal of Smilacina stellata (Liliaceae) fruits. Canadian Journal of Botany, 64(5): 1050-1054.

Pritts, KD,2010. Ginseng: How to find, grow, and use North America's forest gold, 2ed. Stackpole Books, Pennsylvania

Robbins, C. S., 2000. Comparative analysis of management regimes and medicinal plant trade monitoring mechanisms for American ginseng and goldenseal. Conservation Biology 14(5): $1422-1434$.

Russo, S. E., S. Portnoy, \& C. K. Auspurger, 2006. Incorporating animal behavior into seed dispersal models: Implications for seed shadows. Ecology, 87(12): 3160-3174.

Schmidt, V. \& H. M. Schaefer, 2004. Unlearned preference for red may facilitate recognition of palatable food in young omnivorous birds. Evolutionary Ecology Research, 6(6): 919925. 
Schlag, E. M. \& M. S. McIntosh, 2012. RAPD-based assessment of genetic relationships among and within American ginseng (Panax quinquefolius $\mathrm{L}$.) populations and their implication for a future conservation strategy. Genetic Resource Crop Evolution, 59: 1553-1568.

Schupp, E. W., P. Jordano, \& J. M. Gómez, 2010. Seed dispersal effectiveness revisited: a conceptual review. New Phytologist, 188: 333-353.

Sibley, D. A., 2000. The Sibley guide to birds. Knopf. New York. 544 pp.

Smith III, C. G., P. B. Hamel, M. S. Devall, \& N. M. Schiff, 2004. Hermit thrush is the first observed dispersal agent for pondberry (Lindera melissifolia) Castanea, 69(1): 1-8.

Stiles, E. W., 1980. Patterns of fruit presentation and seed dispersal in bird-disseminated woody plants in Eastern deciduous forest. The American Naturalist, 116(5): 670-688.

Souther, S. \& J. B. McGraw, 2011. Local adaptation to temperature and its implications for species conservation in a changing climate. Conservation Biology, 25(5): 922-931.

Souther, S. \& J. B. McGraw, in press. Synergistic effects of climate change and harvest on extinction risk of American ginseng. Ecological Applications.

Swan, D. E., C.C. Hass, D.C. Dalton, \& S. A. Wolf, 2004. Infrared-triggered cameras for detecting wildlife: an evaluation and review. Wildlife Society Bulletin, 32(2):357-365.

Thuiller, W., C. Alber, M. B. Araújo, P. M. Berry, M. Cabeza, A. Guisan, T. Hickler, G. F. Midgley, J. Paterson, F. M Schurr, M. T. Sykes, N. E. Zimmermann, 2008. Predicting global change impacts on plant species distributions: Future challenges. Perspectives in Plant Ecology, Evolution, and Systematics, 9: 137-152.

Trine, C. L., 1998. Wood thrush population sinks and implications for the scale of regional conservation strategies. Conservation Biology, 12(3): 576-585.

Uriarte, M., M. Anciães, M. T. B. Da Silvia, P. Rubim, E. Johnson, \& E. M. Bruna, 2011. 
Disentangling the drivers of reduced long-distance seed dispersal by birds in an experimentally fragmented landscape. Ecology, 92(4): 924-937.

Vander Wall, S. B. \& M.J. Beck, 2012. A comparison of frugivory and scatter-hoarding seeddispersal syndromes. Botanical Review, 78(1): 10-31.

Vander Wall, S. B., K. M. Kuhn, \& J. R. Gworek, 2005. Two-phase seed dispersal: linking the effects of frugivorous birds and seed-caching rodents. Oecologia, 145: 282-287.

Van der Voort, M. E., 2005. An ecological and demographic study of American ginseng (Panax quinquefolius L.) in central Appalachia. Ph.D. dissertation, West Virginia University, Morgantown, West Virginia.

Vega Rivera, J. H., J. H. Rappole, W. T. McShea, \& C. A. Haas, 1998a. Wood thrush postfledging movements and habitat use in Northern Virginia. The Condor: 100(1): 6978.

Vega Rivera, J. H., W. J. McShea, J. H. Rappole, \& C. A. Haas, 1998b. Pattern and chronology of prebasic molt for the wood thrush and its relation to reproduction and migration departure. The Wilson Bulletin, 110(3): 384-392.

Vega Rivera, J. H., W. J. McShea, J. H. Rappole, \& C. A. Haas, 1999. Postbreeding movements and habitat use of adult wood thrushes in Northern Virginia. The Auk, 116(2):458-466.

Vittoz, P. \& R. Engler, 2007. Seed dispersal distances: a typology based on dispersal modes and plant traits. Botanica Helvetica, 117: 109-124.

Wilson, D. E. \& D. M. Reeder (ed), 2005. Mammal species of the world: A taxonomic and geographic reference. The John Hopkins University Press, Baltimore, Maryland.

Wheelwright, N. T., 1985. Fruit size, gape width, and the diets of fruit-eating birds. Ecology, 66(3)808-818. 
Chapter 3: Small mammal seed predation of American ginseng (Panax quinquefolius L.) 


\begin{abstract}
American ginseng (Panax quinquefolius L.) is an uncommon to rare forest herb, wellknown and traded for its medicinal properties. To date, thrushes are the only documented dispersers, but observations of small mammal interactions with ginseng suggest another potential mechanism for dispersal via scatter-hoarding. Game cameras were used to observe small mammal interactions in the field and cafeteria-style feeding boxes were used to observe small mammal feeding behaviors. Additionally, ginseng seedling recruitment at 12 long-term populations was regressed against tree masting indices to investigate whether small mammal population increases after a high tree mast event impact ginseng population demographics. Squirrel species (Family: Sciuridae) were the most frequent small mammals captured in game camera images to interact with ginseng berries. During feeding trials, mice species (Peromyscus sp.) were observed to primarily predate ginseng seeds. Seedling recruitment decreased in response to an increase in hard mast at three populations. Historically, small mammal seed predation may not have significantly impacted population growth, but could be facilitating population decline in ginseng populations with few reproductive individuals.
\end{abstract}

Formatted for submission to the journal Plant Ecology 


\section{Introduction}

American ginseng (Panax quinquefolius L.) is a long-lived perennial forest herb found throughout the Eastern deciduous forest. Well-known for its reputation as a medicinal plant species, wild ginseng has been harvested for trade since the 1700s (Johannsen 2006). Once abundant throughout the forest understory, today ginseng is considered uncommon to rare (McGraw et al. 2003; McGraw et al. 2013). Decline of the species has largely been attributed to harvest of roots for the international medicinal plant trade, and concerns about overharvest led to the species being listed on Appendix II of the Convention on International Trade in Endangered Species of Wild Fauna and Flora (CITES) in 1975 (Robbins 2000). As a species with ecological similarity to other perennial herbs, with rapidly declining populations, and having substantial economic importance, American ginseng has become a model plant species for many demographic as well as conservation studies (reviewed in McGraw et al. 2013).

While ginseng is widely distributed throughout the Eastern deciduous forest, it is found in thousands of small populations that are further characterized by small, clustered groups of individuals (Cruse-Sanders and Hamrick 2004). Although this distribution is thought to be the result of limited dispersal the production of bright red, fleshy berries during the late summer and early fall are beacons within the forest understory that are observed, ingested and dispersed by thrush species (Family: Turdidae) (Hruska et al. in review). However, thrush species may not be the only animals attracted to ginseng berries. Small mammals $(<1 \mathrm{~kg})$ have also been observed interacting with ginseng fruits and seeds (Pritts 2010; Van der Voort 2005; Hruska et al. in review).

Often considered to be primarily granivores, small mammals have also been documented as effective seed dispersers (e.g. Hulme 2002; Van der Wall 2002; Forget et al. 2002; Jansen et 
al. 2004; Vander Wall and Beck 2012). Small mammal interactions with fruits and seeds are widely variable in nature, depending on seed size and abundance, habitat type, species of rodent, and predator presence (e.g. Wang and Chen 2009; Penner and Devenport 2011; Wang et al. 2012; Samuni-Blank et al. 2013; Lobo et al. 2013). Specifically, small mammals in the Eastern deciduous forest are thought to primarily be granivorous larder-hoarders, storing seeds within their burrows, but they have been observed to scatter-hoard hoard seeds in various circumstances, such as during juvenile dispersal or in the presence of a predator (Penner and Devenport 2011;

Elliot 1978 ). Additionally, small mammal hoarding behavior is influenced by the increase in seed abundance of hard mast trees when larger masts are produced (Vander Wall 2002; Schnurr et al. 2002).

The overall objective of this study was to determine if small mammals primarily predate or disperse American ginseng seeds. Specifically, this study asked: (1) Do small mammals frequently interact with ginseng berries? (2) What species of small mammals most frequently interact with berries? (3) How do small mammal interactions with berries compare to thrush interactions? (4)Do small mammals primarily ingest ginseng seeds or scatter hoard berries? (5)Are ginseng seeds still viable when ingested by small mammals? (6) How far do small mammals carry ginseng seeds and what is the fate of these seeds? (7)Does seedling recruitment differ following an increased production by hard mast?

\section{Methods}

Camera-trapping ginseng-small mammal interactions 
In order to observe the frequency of small mammal interactions with ginseng berries, images from infrared, motion-activated wildlife cameras were analyzed. A maximum of seven Moultrie D40 infrared, motion-activated wildlife cameras were placed within six different populations near Morgantown, WV from 2007-2013 (Total populations/Year: 1/2007; 3/2009; $2 / 2010 ; 2 / 2011 ; 3 / 2012 ; 2 / 2013)$. One to three cameras were placed within each population. Cameras were positioned 1-2 $\mathrm{m}$ from a focal plant or group of focal plants using camouflagepainted $1.3 \mathrm{~m}$ tall, $5 \times 10 \mathrm{~cm}$ wooden stakes. Each camera was programmed to take three images when activated, with a one minute delay before it could be triggered again.

For analyses, the three images produced were defined as a single event. Each event was assigned a value $0-5$ to describe the degree of interaction a potential disperser had with focal ginseng plants; zero representing no potential dispersers within the image and 5 representing the highest level of interaction behavior (Hruska et al., in review). Due to small sample sizes, interaction levels 1-5 were divided into two separate categories: Levels 1 and 2 were considered least likely to result in a dispersal event and were labeled Low Level Interactions. Levels 3,4, and 5 were considered most likely to result in a dispersal event and labeled High Level Interactions (Table 3.1). Summary statistics were used to describe total camera days, total events, total number of small mammal potential dispersers $(<1 \mathrm{~kg})$, and total number of large mammal dispersers ( $>1 \mathrm{~kg}$ ). Additionally, a loglikelihood analysis (SAS JMP Statistical Software v10.0; SAS Institute, Cary, North Carolina, USA) was performed to compare the frequency of small mammal ginseng interactions with thrush species interactions, a known disperser of ginseng, where the level of interaction within an event depended on whether a potential disperser was a small mammal or a thrush. 
Table 3.1. Levels of Interaction., adapted from Hruska et al. (in review). Each event, a series of three images per IR-motion activated camera trigger, was assigned a quantitative value to represent the level of interaction a potential disperser (PD) had with American ginseng berries.

\begin{tabular}{|c|c|c|}
\hline & $\mathbf{0}$ & No PD is located within the photograph. \\
\hline$\frac{\ddot{\sigma}}{0} \tilde{\sigma}$ & 1 & $\begin{array}{l}\text { The PD is in photograph and not under the canopy }{ }^{1} \text { of the ginseng plant for two or more } \\
\text { images. }\end{array}$ \\
\hline 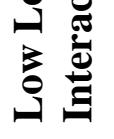 & 2 & $\begin{array}{l}\text { The } \mathrm{PD} \text { is under the canopy }{ }^{1} \text { of the ginseng plant for at least } 2 / 3 \text { images, but it is not } \\
\text { foraging }{ }^{2} \text {. }\end{array}$ \\
\hline \multirow{3}{*}{ 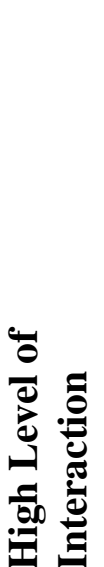 } & 3 & $\begin{array}{l}\text { The PD is under the canopy of the plant in question for at least } 2 / 3 \text { images and is } \\
\text { foraging }{ }^{2} \text {. }\end{array}$ \\
\hline & 4 & $\begin{array}{l}\text { The PD has touched the infructescence. } \\
\text { A berry goes missing between two events, with at one of the events having an identifiable } \\
\text { PD. }\end{array}$ \\
\hline & 5 & $\begin{array}{l}\text { There is a berry within the PD's possession. } \\
\text { Within the three image sequence of an event, a berry has been removed from the } \\
\text { infructescence. }\end{array}$ \\
\hline
\end{tabular}

${ }^{1}$ under canopy: the potential disperser appears below the leaves of the focal ginseng plant ${ }^{2}$ foraging: the potential disperser has its nose or beak to the ground below the leaves of the focal ginseng plant 


\section{Small Mammal Feeding Behavior}

Based on wildlife camera observations of High Level Interactions involving small mammals interacting with ginseng berries and previous observations of apparent seed caches in the field (Van der Voort 2005), cafeteria-style feeding boxes were constructed to observe the feeding behavior of small mammals directly when presented with ginseng and alternative food items (Shahid et al. 2009; Rose 2011). Boxes were placed at sites with known populations of wild ginseng near Rensselaerville, NY and Morgantown, WV during September 2012 and 2013. During September 2012, 10 boxes were placed in one population near Rensselaerville, NY and 20 boxes were placed in two sites (10 boxes/site) near Morgantown, WV. In September 2013, 10 boxes were placed at each of the previous sites and an additional 10 boxes were placed at a second site near Rensselaerville, NY. Boxes were randomly placed within the sites using three $100 \mathrm{~m}$ transects and all boxes were separated by at least $20 \mathrm{~m}$.

Boxes were constructed from $0.625 \mathrm{~cm}$ thick plywood and had $36 \mathrm{~cm}$ x $20 \mathrm{~cm}$ x $20 \mathrm{~cm}$ dimensions to allow for ample animal movement and minimize animal stress (Shahid et al. 2009; Rose 2011). Boxes were equipped with a $5 \mathrm{~cm} \times 5 \mathrm{~cm}$ opening at the front to target small mammal participation. The base was lined with RodoTrack fluorescent tracking powder in order to trace small mammal movements using a black light (Edalgo et al. 2009; Shahid et al. 2009). The back of the box was left open, but covered with $2.5 \mathrm{~cm}$ x $2.5 \mathrm{~cm}$ green plastic perimeter fence material to prohibit entrance and exit from the back, and allow for easy replacement of the food items, as well as the recording of animal activities within the box. Five days prior to placing food within the boxes, peanut butter and oats were used to encourage small mammal visitation (Shahid et al. 2009). 
Three trays were placed within each box and 5 fruits or seeds of three available food items (ginseng, and two other locally-available species) were placed within each tray. The two other food items (in addition to ginseng) included a berry with similar morphology to ginseng (a ripe, red drupe) and an abundant food item from a local overstory tree species. In order to prevent genetic contamination in wild populations, all seeds and fruits, except ginseng, were collected on site, requiring that the additional food items be abundant at a site. Additional food items were spicebush berries (Lindera benzoin L.) and red oak acorns (Quercus sect. Erythroblanus) at WV sites, and Jack in the Pulpit berries (Arisaema triphyllum L.) and Norway spruce seeds (Picea abies L.) at NY sites. Since production of ginseng berries is low in natural populations, "woods grown” ginseng berries (grown under natural tree canopy) were collected directly from plants $1.5 \mathrm{wk}$ prior to the feeding trials and stored at $4^{\circ} \mathrm{C}$. Genetic contamination of the local wild ginseng population by seeds removed from the boxes was mitigated by retrieving the seeds with the aid of the fluorescent tracking powder where possible.

Two Bushnell infrared, motion-activated wildlife cameras were assigned randomly to two different boxes every $24 \mathrm{~h}$ at every site to record the type of small mammals entering the box and their feeding behavior. Cameras were set to record in one minute video segments when triggered, with a $10 \mathrm{~s}$ lag-time between trigger events.

Loglikelihood analyses were performed to determine if small mammal visitation to boxes was different depending on site in both 2012 and in 2013. An additional loglikelihood analysis was performed to determine if small mammal visitation to boxes depended on whether a camera was set up to record visitation on the box. ANOVAs were used to analyze preference for particular food items among sites once non-visited boxes were removed. A three-way ANOVA was used to analyze preference for particular food items at the one site in NY in 2012, where the 
number of fruits removed from a box depended on the species, box location, and day of the experiment. For WV boxes in 2012 and 2013, and NY boxes in 2013, a three-way nested ANOVA was used to determine if the number of food items taken from a box depended on species, the day of the experiment, the site location, and box location within each site. Summary statistics regarding small mammal visitation included: the mean number of food items eaten by a small mammal while in the box, mean amount of time spent inside the box, mean distance travelled after leaving the box, and, where possible, seed fates after a small mammal exited the box. All analyses were performed using SAS JMP Statistical Software Package v. 10.0 (SAS Institute, Cary, North Carolina, USA).

\section{Mast Impacts on Ginseng Recruitment}

Small mammal populations fluctuate dramatically in response to mast seeding by abundant overstory species, particularly increased hard mast such as oak and hickories (e.g. Wolff 1996; Jansen et al. 2004; Clotfelter et al. 2007), leading to the prediction that either during a high mast year, or the year following a mast (depending on responsiveness of the mammal population to increased resources), increased small mammal populations would result in effects on ginseng recruitment. In order to investigate this relationship, we extracted information about seedling recruitment from long term census data of 12 wild ginseng populations in West Virginia. Long-term seed viability in the soil means that the effect of small mammal population peaks on recruitment will be delayed. Seedling recruitment at each population was defined as the number of seedlings to emerge in a given year divided by the number of seeds produced either 21or 33 months prior in that population. The specific time delay used in the formula was based on seed bank/germination experiments conducted at each 
long-term census population from 2007-2011 to determine transition probabilities for matrix models of each population (McGraw et al. 2013).

Yearly mast indices were calculated by the WV Division of Natural Resources (WVDNR) for both hard mast species (hickory, Carya sp.; oak, Quercus sp.; beech, Fagus grandifolia) and two soft mast species (black cherry, Prunus serotina; yellow poplar, Liriodendron tulipifera) based on annual surveys within six geographical regions of West Virginia (2006-2009, 2011; Evans et al. 2006; Evans et al. 2007; Evans et al. 2008, Ryan et al. 2009; Peters et al. 2011; Figure 3.1). Surveyors subjectively evaluated species' mast seedings produced in a location as abundant, common, or scarce (Richmond et al. 2013). Indices were calculated for species within the six geographical areas using the following equation:

Mast Index $=$ [abundant observations /total observations $]+$ [common observations $* 0.5 /$ total observations] $* 100$

(Richmond et al. 2013)

Additionally, the WVDNR calculated an index representing the percent difference of the mast indices in a given year compared to the average historical index for each region, beginning in 1970, which was used for our analyses (Evans et al. 2006; Evans et al. 2007; Evans et al. 2008, Ryan et al. 2009; Peters et al. 2011). Of the 12 ginseng populations in West Virginia, 3 were in the Central Region, 3 were in the Southern Region, and 6 populations were in the Mountains Region (Figure 3.1).

Regressions were performed to determine if the seedling recruitment index at each ginseng population (seedlings at time $\mathrm{t}+21$ mo./ seeds at time $\mathrm{t}$; or seedlings at time $\mathrm{t}+33$ mos./seeds at time $\mathrm{t}$ ) for $\mathrm{t}=$ year of mast and $\mathrm{t}=$ year of mast +1 , depended on increases in hard 
mast crop production. The mast index comparing yearly mast indices to the historical average index for a region was used to observe changes in hard mast crop production. If seedling recruitment was significantly affected by average hard mast, subsequent regressions were completed to determine which specific hard mast species influenced seedling recruitment (Figure 3.2). Significance for all regressions was determined using Student's t-tests. All regressions were performed using SAS JMP Statistical Software Package v. 10.0 (SAS Institute, Cary, North Carolina, USA). 


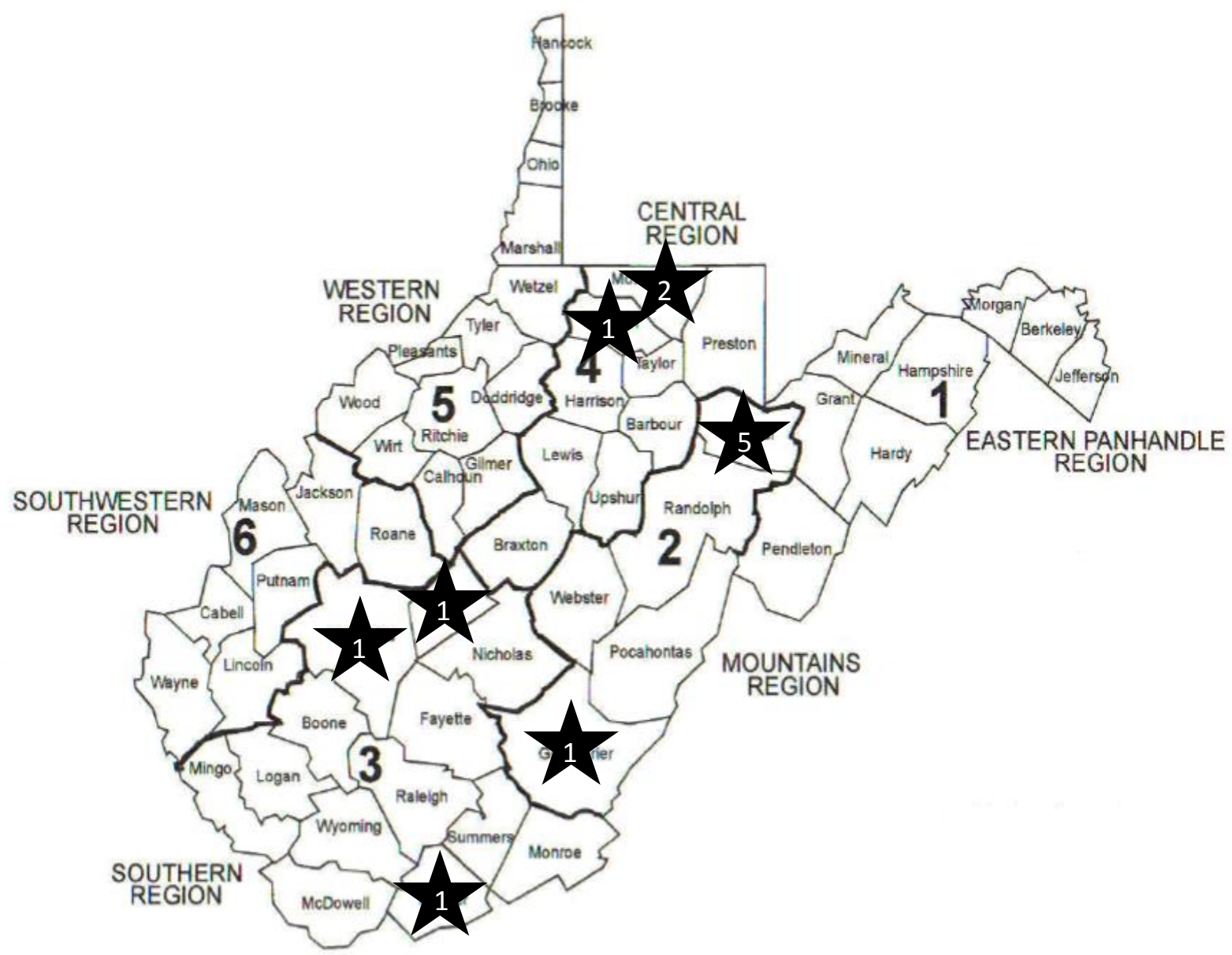

Figure 3.1. Map of WV regions used for mast surveys; regions were labeled 1-5. Starred counties represent the six counties where the twelve long term populations are located (Peters et al. 2011): 5 populations in Tucker County, 2 in Monongalia County, 1 in Marion County, 1 in Kanawha County, 1 in Greenbrier County, and 1 in Mercer County. 
Are hard mast species listed as an overstory species within the population?

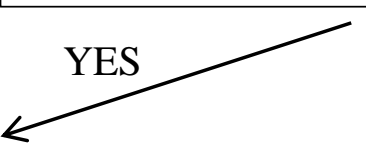

Seedling recruitment was regressed against average hard mast index. Regression was significant?

\begin{tabular}{|c|}
\hline YES \\
$\begin{array}{c}\text { Two more regressions were performed. } \\
\text { 1. Seedling recruitment v. average } \\
\text { oak mast index }\end{array}$ \\
2. Seedling recruitment v. average non-oak \\
hard mast index \\
$\qquad \begin{array}{c}\text { 2. Seedling recruignificantly affected } \\
\text { non-oak mast }\end{array}$ \\
\hline $\begin{array}{c}\text { Two more regressions were performed. } \\
\text { 1. Seedling recruitment v. average } \\
\text { hickory index }\end{array}$ \\
2. Seedling recruitment v. average beech \\
index \\
\hline
\end{tabular}

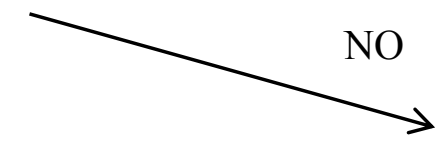

No regression or additional regression was performed.

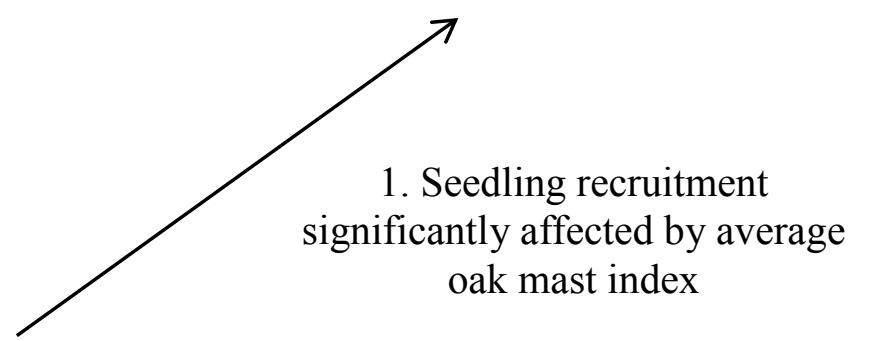

Figure 3.2. Diagram depicting the procedure for investigating the relationship between seedling recruitment of seeds produced both during and the year immediately following a given mast year with the average hard mast index at each population. 


\section{Results}

Ginseng-Animal Interactions

Over 241 camera-days, a total of 925 camera-triggered events occurred. Of the 925 camera-triggered events, 647 of the events had no identifiable potential disperser (Level 0 Interaction; Table 3.1). Of the events with potential dispersers, there were 48 events with identified avian potential dispersers and 230 events with identified mammalian potential dispersers. Of the avian potential dispersers, thrush species (Family: Turdidae) were found to have High Level Interactions (Table 3.1: Levels 4 and 5) with ginseng infructescences most frequently and to disperse seeds (Hruska et al., in review).

Of the identified mammalian dispersers, $78.2 \%$ were squirrel species (Family: Sciuridae) and new world mice species (Family: Cricetidae). Large mammal potential dispersers, primarily raccoons (Procyon lotor; $\mathrm{n}=22$ ) and Virginia opossums (Didelphis virginiana; $\mathrm{n}=17$ ), accounted for $22 \%$ of events with identified dispersers and were all Low Level Interactions. All High Level Interactions were squirrel species. Eastern chipmunks (Tamias striatus) were most frequently identified as having High Level Interactions with ginseng berries ( $\mathrm{n}=12) . \quad$ In 5 events, Eastern chipmunks interacted directly with ginseng infructescences (Table 3.1: Level 4 and 5 Interaction), while in the remaining 7 events chipmunks were foraging below focal ginseng plant(s) (Table 3.1: Level 3 Interaction). Events where Eastern chipmunks directly interacted with ginseng, the series of three images most frequently show the chipmunk removing a berry and sitting below the plant with its hands to its mouth, suggestive of eating (Figure 3.3). Eastern gray squirrels (Sciurus carolinensis) were identified in two High Level Interactions, and demonstrated foraging behavior below the focal ginseng plant(s) in both cases. One Fox squirrel (Sciurus niger) also demonstrated a High Level Interaction. Compared to squirrel species 
interactions, when thrush species interact with ginseng it is more likely to result in High Level Interactions with ginseng infructescences (Figure 3.4: $\chi^{2}=6.239, \mathrm{p}=0.0300$ ). However, in total squirrel species had a more High Level Interactions $(n=15)$ compared to thrush species $(n=10)$. 


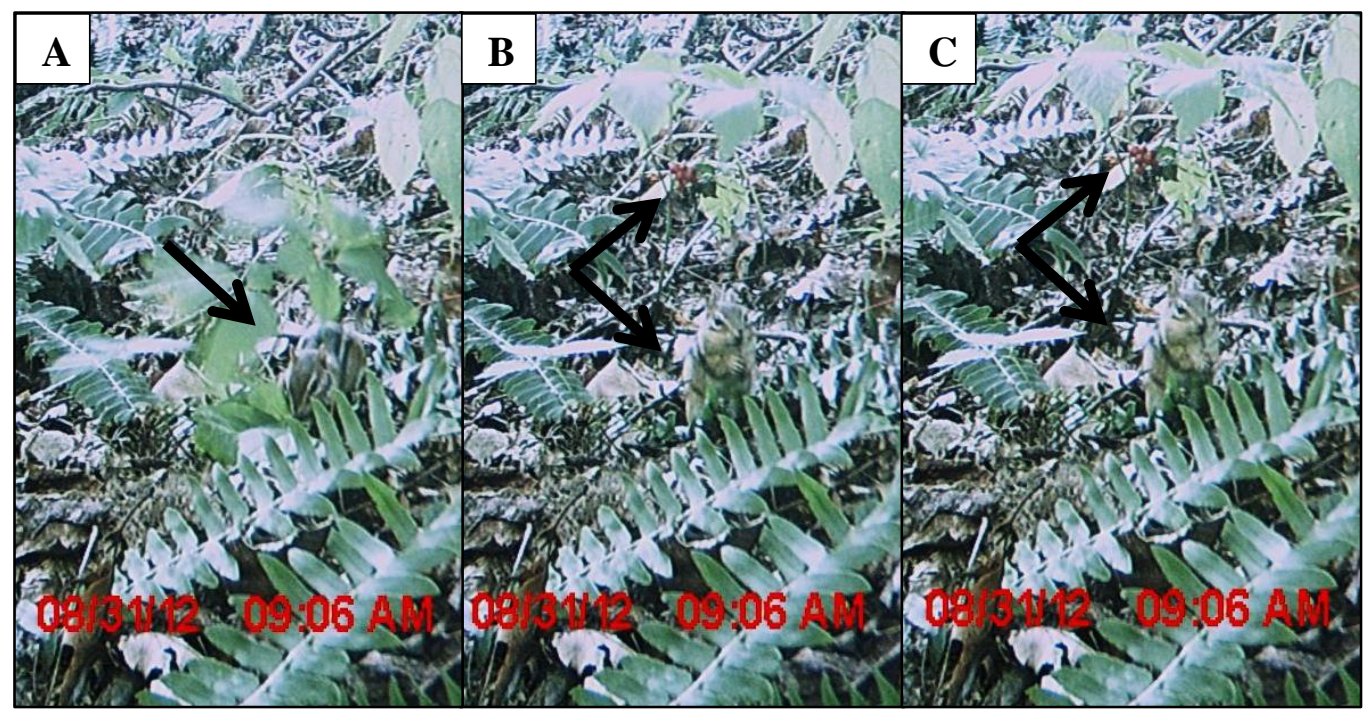

Figure 3.3. Game camera images displaying an Eastern chipmunk exhibiting High Level

Interaction behavior. A. Eastern chipmunk has pulled ginseng plant to the ground via the infructescence. B and C. Eastern chipmunk sits below the ginseng plant with a suspected berry in its paws. 


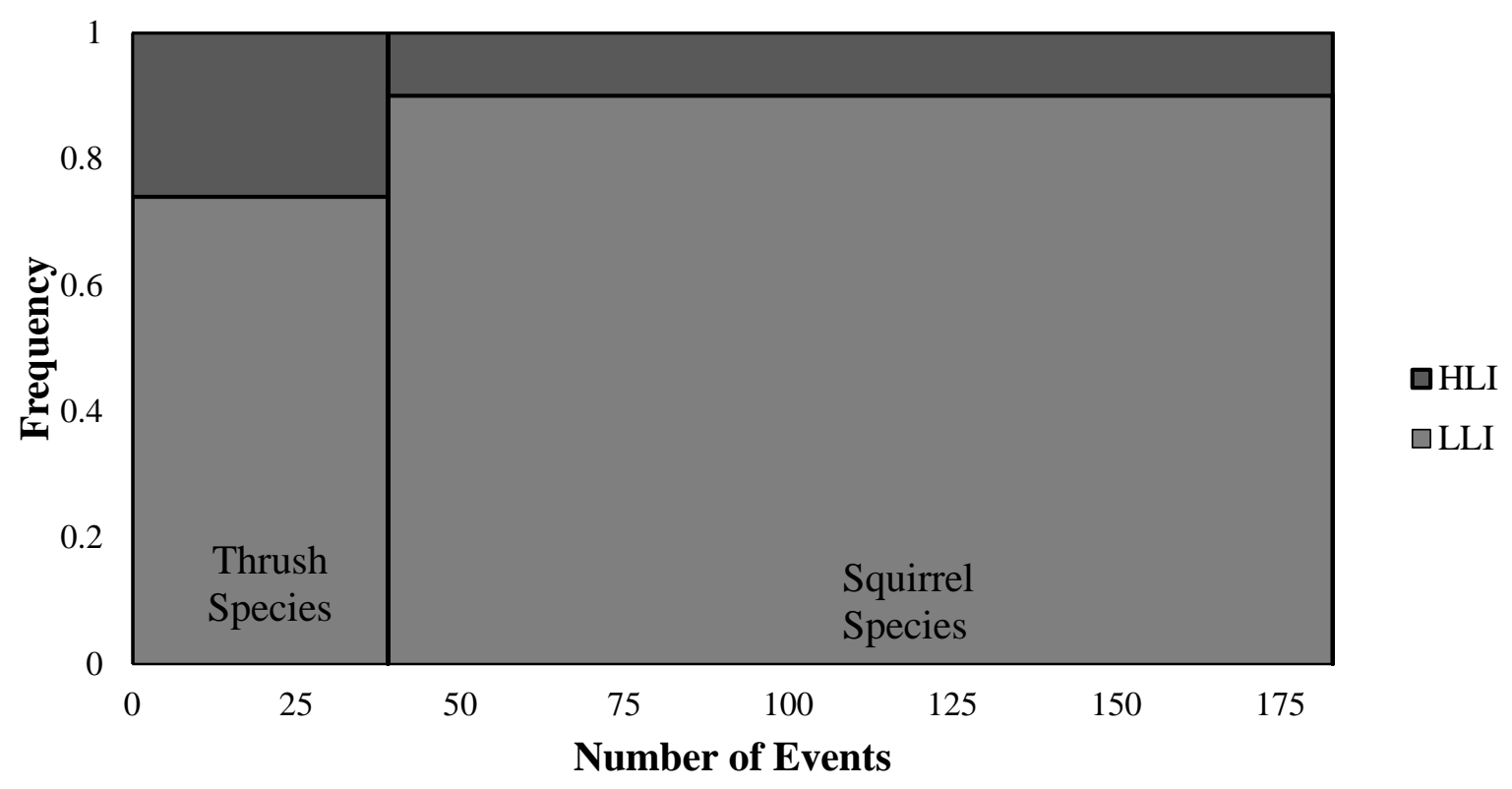

Figure 3.4. Partitioning of thrush and squirrel potential disperser events based on categories that would least likely result in a dispersal event (LLI: Low Level of Interaction) and most likely result in a dispersal event (HLI: High Level of Interaction), when foraging behavior is included as a HLI. 


\section{Feeding Behavior}

During 2012 and 2013 feeding trials, relative rates of small mammal visitation to feeding boxes differed between NY and WV sites (Figure 3.5). In 2012, boxes at NY10 were more than twice as likely to be visited per day compared to boxes at both WV31 and WV37 $\left(\chi^{2}=68.563\right.$; p<0.0001). However, during the 2013 feeding trials, boxes at WV31 and WV37 sites were more than twice as likely to be visited by small mammals as boxes at both NY sites $\left(\chi^{2}=72.62\right.$; $\mathrm{p}<0.0001)$.

The food items most frequently eaten or removed from feeding boxes differed between both sites and years (Figure 3.6). In 2012, the number of boxes visited at WV31 and WV37 was too low to allow a comparison of the number of food items eaten or removed, however, American ginseng seeds were most frequently eaten or removed from feeding boxes at NY10 $\left(F_{\text {species }}=128.594, p<0.0001\right)$. In 2013, American ginseng was the food item most frequently eaten or removed at both WV31 and WV37, followed by spicebush berries $\left(\mathrm{F}_{\text {species }}=34.614\right.$, $\mathrm{p}<0.0001)$. Norway spruce seeds were the most frequently eaten or removed food item from boxes at NY10, while no food item was eaten or removed more frequently than others at NY11 $\left(\mathrm{F}_{\text {species }}{ }_{\text {site }}=12.0403, \mathrm{p}=0.0002\right)$.

Overall, the presence of a video camera did not influence small mammal visitation to the feeding boxes $\left(\chi^{2}=0.114 ; p=0.7361\right)$. A total of $252 \mathrm{~min}$ of video data were gathered from all sites over the two years. In total, video cameras were triggered 83 times due to visitors present within the feeding boxes. Mice (Peromyscus sp.) were the most frequent visitor to trigger video cameras $(n=72)$, followed by Eastern chipmunks $(n=7)$. The remaining visitors included two Eastern gray squirrels, one Carolina wren (Thryothorus ludovicianus), and one large field cricket 


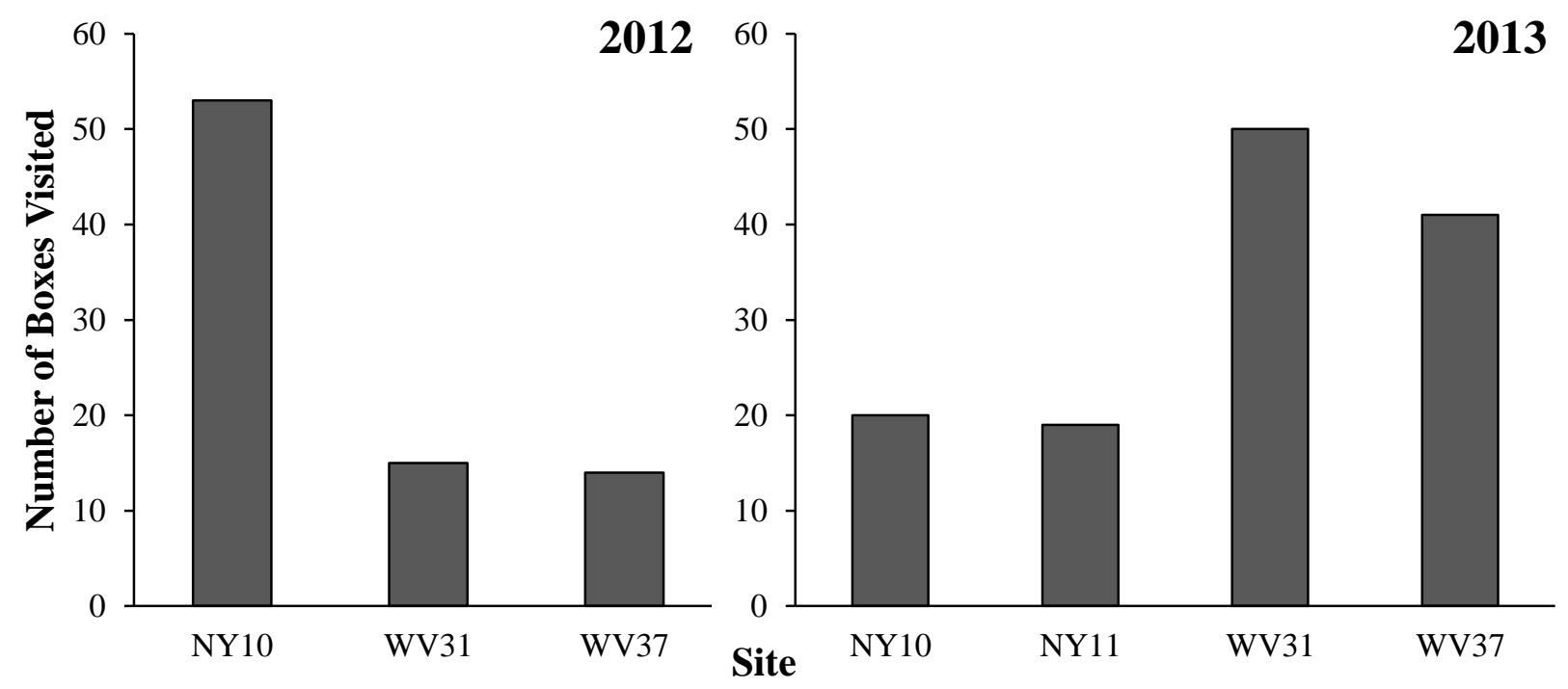

Figure 3.5. The total number of boxes visited at both NY and WV sites over a six day period in 2012 and a five day period in 2013. 

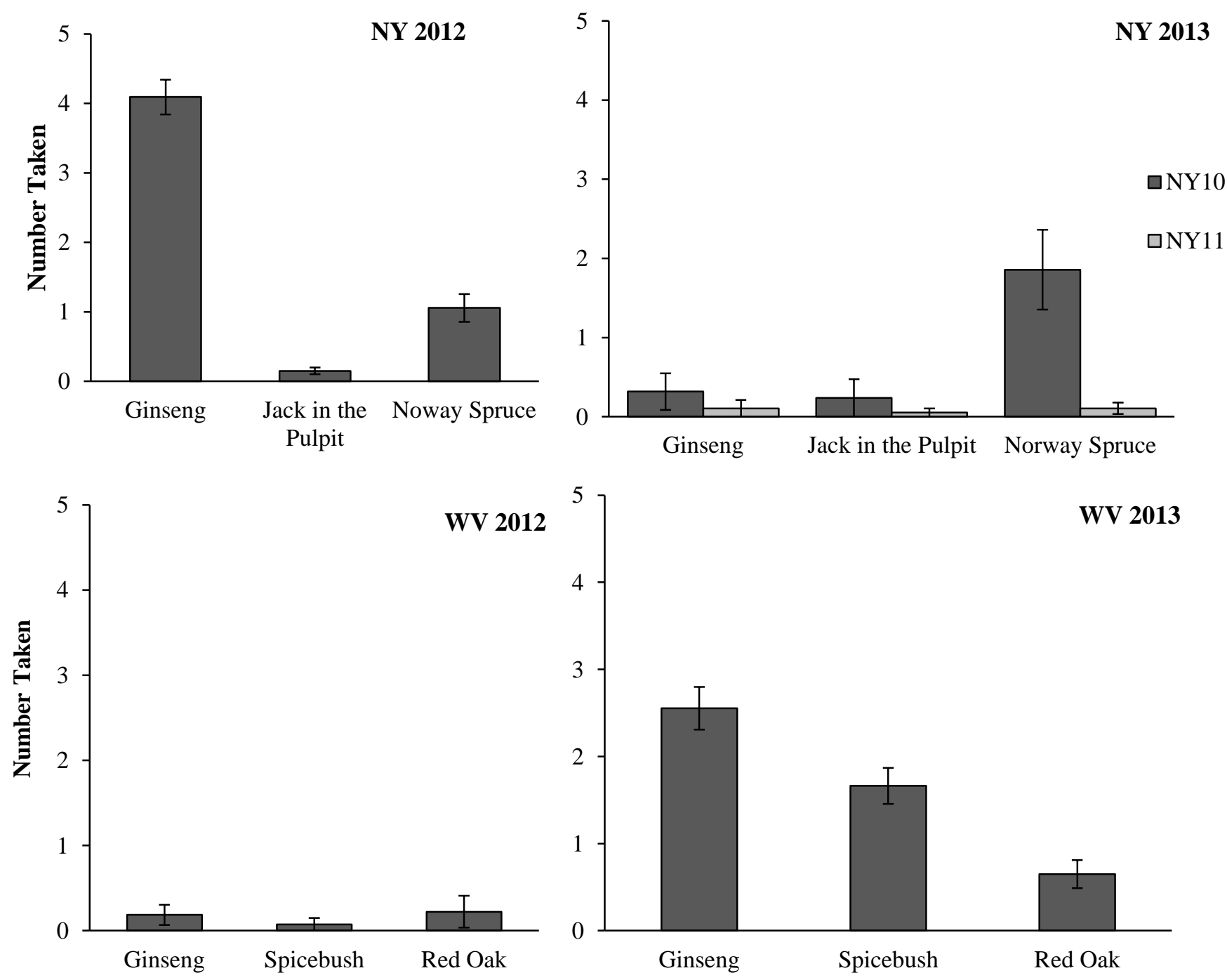

Figure 3.6. Food item selection at NY and WV sites in 2012 and 2013. Number of food items taken refers to the number of food items either eaten within the box or removed from the box. NY sites are differentiated in 2013 because the number of food items taken depended on the site. 
(Gryllus pennsylvanica). Visitors were inside the box for an average of $24.6 \mathrm{~s}+/-2$ (mean +/S.E.), with a minimum time of $1 \mathrm{~s}$ and a maximum time of $60 \mathrm{~s}$. Of 83 recorded visits, 22 videos displayed instances of mice eating one or more available food items within the boxes. Video footage showed 22 instances of mice species eating American ginseng berries, 3 of mice eating Jack in the Pulpit, 2 of mice eating Norway spruce seeds, and 1 of a mouse eating a spicebush berry. All videos show mice species eating the food items within the feeding boxes and not removing or hoarding them. Mice would target the embryo of the seed during mastication, leaving behind remnants of shredded pulp and seed coats (Figure 3.7).

Video recordings demonstrated that ginseng seeds were primarily masticated by small mammals within feeding boxes, but there were 44 instances where food items were shown to be removed from feeding boxes using the fluorescent tracking powder. There were eighteen events where removed food items were tracked to mouse burrows a mean of $2.68 \mathrm{~m}(+/-0.35 \mathrm{~m})$ away from the box and eight events where tracking powder led to masticated ginseng seeds within leaf litter $(1.28 \mathrm{~m}+/-0.41 \mathrm{~m})$. However, there were 18 instances where seeds were not accounted for. In two of these instances, tracking powder led to two sites that appeared to have been intensely disturbed, potentially due to digging and/or pilfering of a scatter-hoard. The remaining 16 instances were unable to be tracked over $0.7 \mathrm{~m}(+/-0.1 \mathrm{~m})$ either due to too much precipitation the night before or too much sunlight. 


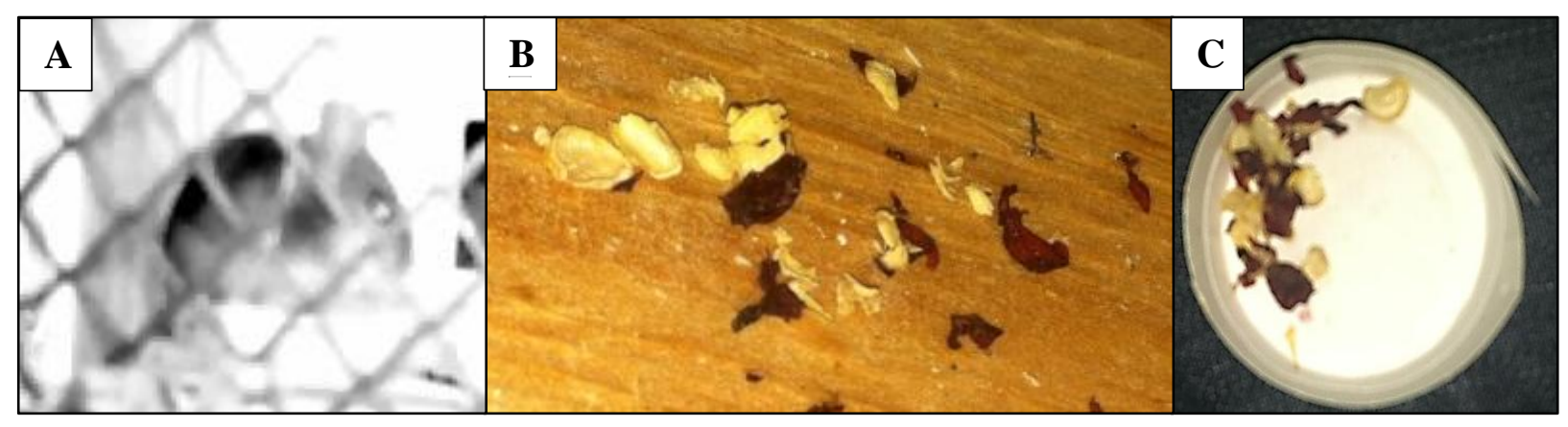

Figure 3.7. Images of mice feeding behavior within box. A. Still image from video camera of mouse masticating ginseng berry. B. Ginseng pulp and seed coat remnants found along the bottom of a feeding box with seed embyros missing. C. Ginseng pulp and seed coat remnants in ginseng feeding tray. 
Impacts of Mast on Seedling Recruitment in WV

Nine of the twelve ginseng populations studied had at least one hard mast species documented as an overstory species. In total, 18 regressions were completed to determine if the recruitment of seeds produced at time $t$ and at time $t+1$ depended on the production of hard mast crops (Table 3.2). Of the twelve populations, two (WV22, WV27) demonstrated a negative relationship between seedling recruitment of seeds produced during a high mast year $(\mathrm{t})$ and hard mast species, and one population (WV26) demonstrated a negative relationship between mast index and the seedling recruitment index of seeds produced the year after a high mast year $(t+1)$ (Table 3.2). An additional 6 regressions were completed to determine specific species effects on recruitment at these sites. At WV27, the overall negative effect of elevated hard mast on seedling recruitment (21 months post-dispersal) appeared to be specifically related to oak masting as the regression on this species' mast index was also statistically significant (Figure 3.8A; Student's $\mathrm{t}=-3.90 ; \mathrm{p}=0.0299)$. Likewise, for WV 26 seedling recruitment ( 21 months post-dispersal) of seeds produced one year following a mast decreased with increased average oak mast (Figure 3.8B; Student's $t=-5.10 ; \mathrm{p}=0.0364)$. At WV 22, seedling recruitment (33 months post-dispersal) decreased two years following an increased beech mast (Figure 3.8C; $\mathrm{t}=$ 5.80; $\mathrm{p}=0.0284$ ). Additionally, black cherry, a soft mast species, was found to be an abundant overstory tree at WV30 and seedling recruitment both at $\mathrm{t}$ and $\mathrm{t}+1$ was regressed against black cherry mast. Seedling recruitment at WV30 decreased with increased black cherry mast, a soft mast species (Figure 3.8D; Student's $t=-7.15 ; \mathrm{p}=0.0056$ ). 
Table 3.2. Table of regression results for the twenty regressions comparing seedling recruitment indices $(\mathrm{y})$ to hard mast indices $(\mathrm{x})$ for seeds produced the year of a mast $(\mathrm{t})$ and the year following a mast $(\mathrm{t}+1)$.

\section{Site Seeds Produced the Year of a Mast (t)}

WV21

$$
y=0.0034 x+0.3097
$$

Student's $t=0.36 ; p=0.7556$

WV22

WV24

WV25

WV26

WV27

WV28

WV29

WV30

$$
y=-0.0055 x+0.2594
$$

Student's $\mathrm{t}=-5.25 ; \mathbf{p}=\mathbf{0 . 0 3 4 4}$ *

$$
y=0.0041 x+0.2556
$$

Student's $t=0.64 ; p=0.5679$

$$
y=2.59 * 10^{\wedge}-5 x+0.2597
$$

Student's $t=0.02 ; p=0.9866$

$$
y=0.0012 x+0.2608
$$

Student's $t=0.44 ; p=0.6890$

$$
y=-0.0021 x+0.1577
$$

Student's $\mathrm{t}=-7.24 ; \mathbf{p}=\mathbf{0 . 0 0 5 4}$ *

$$
y=0.0026 x+0.3891
$$

Student's $t=0.30 ; p=0.7913$

$$
y=-0.004548 x+0.1936
$$

Student's $t=-0.60 ; p=0.6083$

$$
\begin{gathered}
y=-0.0003 x+0.2034 \\
\text { Student's } t=-0.17 ; p=0.8746
\end{gathered}
$$

\section{Seedlings}

\section{Seeds Produced the Year Following a Mast (t+1)}

$$
y=0.0095 x+0.3939
$$

Student's $t=1.72 ; p=0.2270$

$$
y=0.0041 x+0.3129
$$

Student's $t=1.68 ; p=0.2346$

$$
y=0.0080 x+0.3
$$

Student's $t=2.24 ; p=0.1539$

$$
y=-0.0012 x+0.2885
$$

Student's $t=-2.33 ; p=0.1456$

$$
y=-0.0126 x+0.1601
$$

Student's $\mathrm{t}=-18.97 ; \mathbf{p}=\mathbf{0 . 0 0 2 8} *$

$$
y=-0.0016 x+0.2065
$$

Student's $t=-0.98 ; p=0.4312$

$$
y=0.0038 x+0.4034
$$

Student's $t=0.45 ; p=0.6995$

$$
y=-0.00132 x+0.2489
$$

Student's $t=-0.16 ; p=0.8893$

$$
y=-0.0021 x+0.1941
$$

Student's $t=-0.43 ; p=0.7088$ 


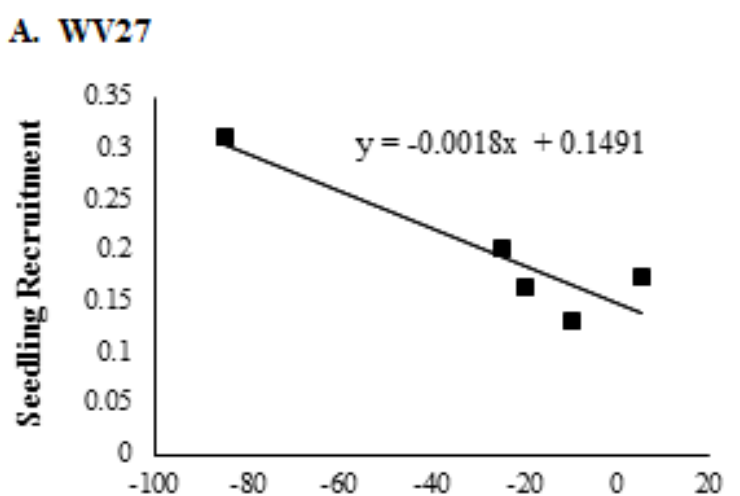

C. WV22

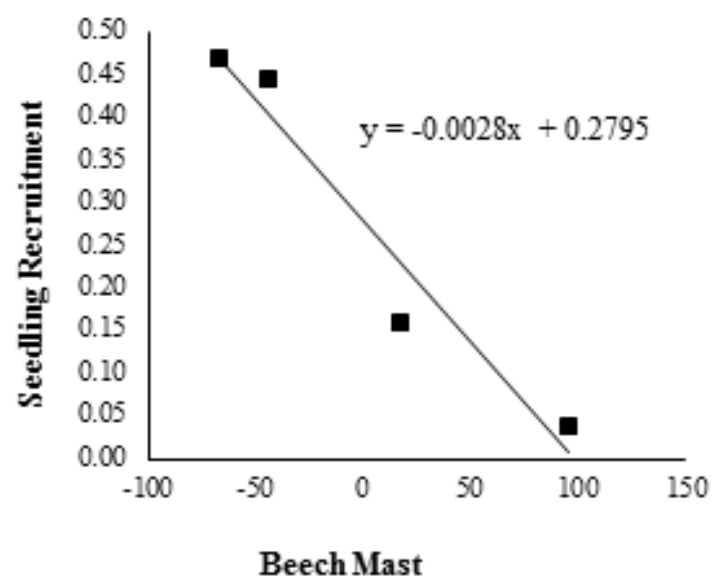

B. WV 26

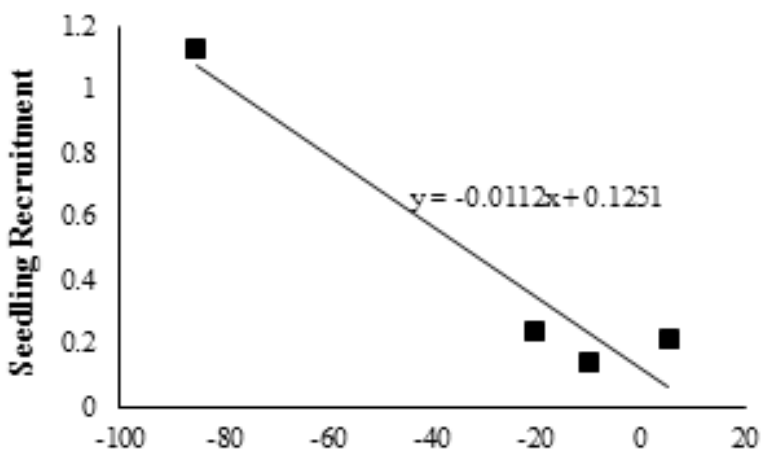

Oak Mast

\section{WV30}

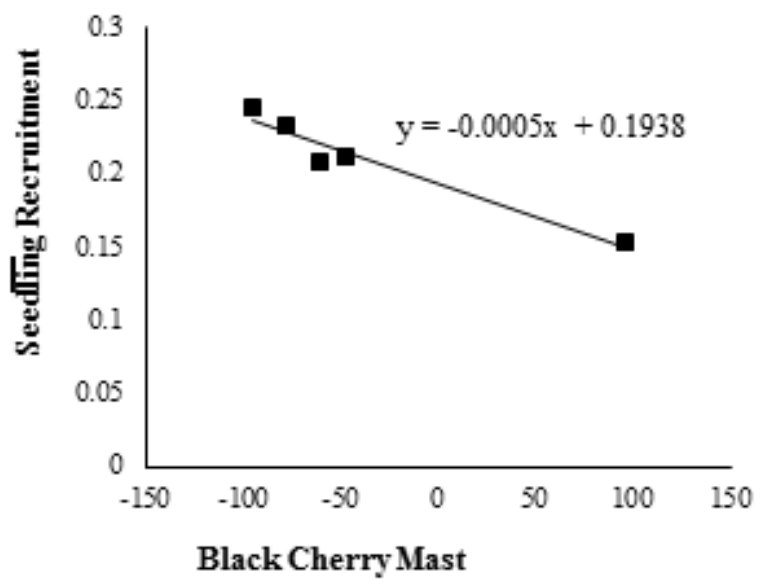

Figure 3.8. Yearly seedling recruitment indices regressed against the percent difference of the yearly average mast indices compared to the historical average index. A. Yearly seedling recruitment indices at WV 27 as a function of the percent difference of oak mast indices. B. Yearly seedling recruitment indices at WV26 as a function of percent difference of oak mast. C. Yearly seedling recruitment indices at WV22 as a function of percent difference of beech mast. D. Yearly seedling recruitment indices at WV30 as a function of percent difference of black cherry mast. 


\section{Discussion}

Camera-trapping and cafeteria box observations identified squirrel species (including chipmunks) and mice as the principal small mammal species showing interest in ginseng infructescences. A greater number of squirrel species were observed directly interacting with ginseng berries using camera-trapping, while mice species were the primary species to interact and predate ginseng seeds in cafeteria boxes. This discrepancy may be due to the inefficiency of wildlife cameras at capturing mice interactions with ginseng berries or because feeding boxes inhibited squirrel visitation. Both seem likely to have biased our observations of ginseng-small mammal interactions. The small size of mice, their quick movements, and camouflage within the leaf litter may have prevented the triggering of camera traps or their detection within the images (Swann et al. 2004; Glen et al. 2013). Conversely, while chipmunks and squirrels were able to enter the feeding boxes, the small entrance may have discouraged chipmunks and squirrels.

The frequency of small mammal visitation to feeding boxes each day at the WV and NY sites also differed between 2012 and 2013. During 2012, in NY the visitation rate (per box-day) was higher than observed in WV and but the reverse occurred in 2013. One hypothesis is that visitation to boxes was more frequent following a high mast year. During 2012, WV sites were experiencing a high mast year (Richmond et al. 2012), while it was the year after a mast in NY (O’Neal, personal communication, 2012). This could have created a scenario in WV in which average, or below average, small mammal populations had an abundance of food resources along the forest floor and therefore were less likely to enter feeding boxes in search of food. In NY, an above average small mammal population would have had limited food resources and thus may have been more likely to search for food within feeding boxes. In 2013, small mammal 
populations in $\mathrm{WV}$ would then have above average small mammal population with limited resources and be more inclined to search for food items in feed boxes (Richmond et al. 2013). Small mammal populations in NY would have decreased after a year of limited food resources causing them to be less incline to search for food resources within feeding boxes.

With respect to ginseng seed fate, small mammals, such as mice and chipmunks, are expected to act primarily as granivores. Still images from wildlife cameras showed two instances of High Level Interactions where a chipmunk pulled a ginseng infructescence to the ground, appeared to remove a berry, and sat below the canopy of the plant with forefeet in feeding position relative to the mouth, suggestive of eating. Ginseng seeds are $3-5 \mathrm{~mm}$ in length and covered with a hard seed coat. However, in images and video, small mammals were observed chewing through the seed coat without difficulty. Small seeds, such as ginseng, are more likely to be eaten when encountered than hoarded by small mammals (e.g. Vander Wall 2010; Wang et al. 2012; Rusch et al. 2013). Additionally, most wild ginseng populations are small and do not produce large amounts of seed, another characteristic of plant reproduction that has been shown to reduce scatter-hoarding behavior in small mammals (Vander Wall 2002; Vander Wall 2010).

Ginseng was once more abundant on the forest floor than it is today (McGraw et al. 2013). At higher reproductive plant densities, small mammals may have played a more significant dispersal role. Van der Voort placed seeds in transects at two different densities (2000 berries/5m and 2000 berries $/ 50 \mathrm{~m}$ ) to observe seedling emergence and survival (Van der Voort 2005). When locating newly emerged seedlings, 12 caches were located at varying distances from the high density transects (2000 berries $/ 5 \mathrm{~m})$ with as many as 50 seedlings within a cache (Van der Voort pers. obs. 1996-2000; Van der Voort 2005); suggesting that small 
mammals may facilitate seed dispersal in populations with higher seed production. While, these events may currently be rare due to limited seed production in the wild, such dispersal events may have happened frequently when ginseng was more abundant. Dispersal events by small mammals are considered advantageous for plant dispersal because seeds are not exposed to digestive processes that may leave seed embryos inviable, they are deposited in large numbers, and they are buried near the soil surface (Penner and Devenport 2011; Vander Wall and Beck 2012).

When investigating the effect of tree mast years on seedling recruitment, there was not a consistent decrease in recruitment from seeds produced either the year of a mast or the year following a mast at long term census populations in WV. Only at one population was there a decrease in the number of seedlings recruited from seeds produced one year after a hard mast (WV26: Figure 6B); which is what would be expected if recruitment was being impacted by an increase in small mammal populations following a mast year (Wolff 1996). However, two populations demonstrated a decrease in seedling recruitment from seeds produced the year of a hard mast (WV 27 and WV22; Figures 6A and 6C). Relationships between recruitment at WV26 and WV27, both located in similar areas within the Central Region, may have been detectable because these populations produce relatively small amounts of seeds with high germination probabilities at 21 months after being added to the seed bank. During the 2007-2011 investigation into seed bank dynamics, greater than $50 \%$ of seeds added to the seed bank germinated at 21 mos., with less than $20 \%$ at 33 mos., and less than $10 \%$ at 45 mos. However, two other populations with hard mast species in the canopy were documented to have similar distribution of germination probabilities (WV24 and WV25) but do not demonstrate a strong decrease in seedling recruitment from seeds produced either the year of the mast or the year 
following a mast. This could be due to the limited sample size and low variation in the mast indices at WV24 and WV25. The difference between the highest and lowest average hard mast indices at WV26 and WV27 was 79, whereas at WV24 and WV25 the difference between the highest and lowest average hard mast indices was 24 and 69, respectively.

Germination probabilities at other West Virginia sites are more evenly distributed between 21 mos., 33 mos., and 45 mos. post-dispersal, decreasing the probability of showing a relationship between seedling recruitment and masting since recruitment effects would be spread out over multiple years. Therefore, an effect may have been occurring in these populations, but did not show up in the regressions. Variation in dormancy of ginseng seeds in the seed bank would be advantageous for populations with fluctuating mast and small mammal predation by allowing for the persistence of ginseng in the seed bank and seedling recruitment after a year of low seed production or high predation (Nathan and Muller-Landau 2000).

Ginseng seeds may be able to persist in the seed bank at many populations for as long as 45 mos. post-dispersal, but small mammal predation may still have a negative impact on seedling recruitment by decreasing the total input of seeds into the seed bank and this impact may be accentuated at low population sizes. Small mammals are most likely to scatter-hoard seeds when they are produced in mass quantities. The historical, intense harvest of reproductive individuals from ginseng populations may have increased seed predation rate by decreasing the total number of seeds produced within a population. During tree mast years, small mammals are expected to primarily rely on the fruits of trees, as they are larger in size and more abundant (Vander Wall 2010). But, during the years between large tree mast events, small mammals must rely more on the fruits of forest herbs. If small mammal primarily masticate or larder-hoard the seeds instead of scatter-hoarding the seeds, seedling recruitment would decrease. Low seed production is not 
an uncommon characteristic of long-lived understory herbs. However, little research has been done to examine the impacts of small mammal seed predation on understory herbs, particularly during and following tree mast events. Additional research is also needed in order to compare the consequences of seed predation for uncommon to rare herbs and their more abundant counterparts (Combs et al. 2013). Evidence from the present study suggests that small mammals may have been historically crucial for ginseng dispersal, but under current conditions, small mammals primarily predate ginseng seeds.

\section{Acknowledgements}

We would like to thank J. Chandler, J. Turner, A. Wagner, W. Bailey, M. Elza, and C. Mallow for their help with camera set up, image collection, and cafeteria box observations. Financial support was received from the Edmund Niles Huyck Preserve and from the National Science Foundation Long Term Research in Environmental Biology Grant (NSF grant DEB0613611 and DEB-1118702 to JBM). Feeding trials were conducted under Animal Care and Use Protocol 12-0806.

\section{Literature Cited}

Clotfelter, ED, Pedersen AB, Cranford JA, Ram N, Snajdr EA, Nolan Jr. V, Ketterson ED (2007) Acorn mast drives long-term dynamics of rodent and songbird populations. Oecologia 154: $493-503$

Combs, JK, Lambert AM, Reichard SH (2013) Predispersal seed predation is higher in a rare species than in its widespread sympatric congeners (Astragalus, Fabaceae). Amer J Bot 100(11): 2149-2157.

Cousens R, Dytham C, Law R (2008) Dispersal in plants: A population perspective. Oxford University Press, Oxford 
Cruse-Sanders JM, Hamrick, JL (2004) Spatial and genetic structure within populations of wild American ginseng (Panax quinquefolius L. Araliaceae). J Hered 95(4): 309-321

Edalgo JA, McChesney HM, Love JP, Anderson JT (2009) Microhabitat use by white-footed mice Peromyscus leucopus in forested and old-field habitats occupied by morrow's honeysuckle Lonicera morrowii. Curr Zool 55(2): 111-122

Elliot, L (1978) Social behavior and foraging ecology of the Eastern chipmunk (Tamias striatus) in the Adirondack Mountains. Smithsonian Contributions to Zoology, Smithsonian Institution Press, Washington D.C.

Evans JE, Tucker RL, Igo WK, Richmond E (2006) 2006 West Virginia Mast Survey and Hunting Outlook. WV Division of Natural Resources Section. http://www.wvdnr.gov/hunting/PDFFiles/2006MASTSURVEYfinal2.pdf. Accessed 14 March 2014

Evans JE, Tucker RL, Igo WK, Richmond E (2007) 2007 West Virginia Mast Survey and Hunting Outlook. WV Division of Natural Resources Section. http://www.wvdnr.gov/hunting/PDFFiles/2007MASTSURVEY.pdf. Accessed 14 March 2014

Evans JE, Tucker RL, Igo WK, Richmond E (2008) 2008 West Virginia Mast Survey and Hunting Outlook. WV Division of Natural Resources Section. http://www.wvdnr.gov/hunting/PDFFiles/2008MASTSURVEY.pdf. Accessed 14 March 2014

Forget PM, Hammond DS, Milleron T, Thomas R (2002) Seasonality of fruiting and food hoarding by rodents in Neotropical forests: Consequences for seed dispersal and seedling 
recruitment. In: Levey DG, Silva WR, Galettie M (eds) Seed Dispersal and Frugivory: Ecology, Evolution and Conservation. CAB International Press, Oxfordshire, 241-256

Glen AS, Cockburn S, Nichols M, Ekanayake J, Warburton B (2013) Optimising camera traps for monitoring small mammals. PLOS One 8(6): 1-7

Hulme PE (2002) Seed-Eaters: Seed Dispersal, Destruction and Demography In: Levey DJ, Silva WR, Galettie M (eds) Seed Dispersal and Frugivory: Ecology, Evolution and Conservation. CAB International Press, Oxfordshire, 257-273

Hruska AM, Souther S, McGraw JB (2014) Songbird dispersal of American ginseng (Panax quinquefolius). Submitted 02/25, in review

Johannsen, K (2006) The Secret World of America's Most Valuable Plant. The University Press of Kentucky, Lexington

Jansen PA, Bongers F, Hemereik L (2004) Seed mass and mast seeding enhance dispersal by neotropical scatter hoarding rodent Ecol Monogr 74(4) 569-589

Lobo N, Green DJ, Millar JS (2013) Effects of seed quality and abundance on the foraging behavior of deer mice. J Mammal 94(6): 1449-1459

McGraw JB, Lubbers AE, Van der Voort M, Mooney EH, Furedi MA, Souther S, Turner JB, Chandler J (2013) Ecology and conservation of ginseng (Panax quinquefolius) in a changing world. Ann NY Acad Sci 1286(1): 62-91

McGraw JB, Sanders SM, Van der Voor ME (2003) Distribution and abundance of Hydrastis canadensis L. (Ranunculaceae) and Panax quinquefolius L. (Araliaceae) in the Central Appalachian Region. J Torr Bot Club 130: 62-69

Nathan R, Muller-Landau HC (2000) Spatial patterns of seed dispersal, their determinants and consequences for recruitment. TREE 15(2): 278-285 
Pearson RG, Dawson TP (2003) Predicting the impacts of climate change on the distribution of species: are bioclimate envelop models useful? Global Ecol Biogeogr 12: 361-371

Penner JL, Devenport LD (2011) A comparative study of caching and pilfering behavior in two sympatric species, least chipmunks (Tamias minimus) and Eastern chipmunks (Tamias striatus). J Comp Psycho 125(4): 375-384

Peters ML, Igo WK, Ryan CW, Tucker RL (2011) 2011 West Virginia Mast Survey and Hunting Survey and Hunting Outlook. WV Division of Natural Resources Section. http://www.wvdnr.gov/hunting/pdffiles/2011westvirginiamastsurvey.pdf. Accessed 14 March 2014

Pritts, KD (2010) Ginseng: How to find, grow, and use North America’s forest gold, 2ed. Stackpole Books, Pennsylvania

Richmond E, Ryan CW, Tucker RL, Peters ML (2012) 2012 West Virginia Mast Survey and Hunting Outlook. WV Division of Natural Resources Section. http://www.wvdnr.gov/hunting/PDFFiles/2012westvirginiamastsurvey. Accessed 14 March 2014

Richmond E, Ryan CW, Tucker RL, Peters ML (2013) 2013 West Virginia Mast Survey and Hunting Outlook. WV Division of Natural Resources Section. http://www.wvdnr.gov/hunting/PDFFiles/2013westvirginiamastsurvey. Accessed 14 March 2014

Robbins CS (2000) Comparative analysis of management regimes and medicinal plant trade monitoring mechanisms for American ginseng and goldenseal. Cons Biol 14(5): 14221434 
Rose CL (2011) Evaluating the effects of Morrow's honeysuckle control on vertebrate and vegetation assemblages, and small mammal foraging ecology at Fort Necessity National Battlefield. MSc thesis, West Virginia University

Rusch UD, Midgley JJ, Anderson B (2013) Rodent consumption and caching behavior selects for specific seed traits. S Afr J Bot 84: 83-87

Ryan CW, Tucker RL, Richmond E, Igo WK (2009) 2009 West Virginia Mast Survey and Hunting Outlook. WV Division of Natural Resources Section. http://www.wvdnr.gov/hunting/PDFFiles/2009westvirginiamastsurvey. Accessed 14 March 2014

Samuni-Blank M, Arad Z, Dearing MD, Gerchman Y, Karasov WH, Izhaki I (2013) Friend or foe? Disparate plant-animal interactions of two congeneric rodents. Evol Ecol 27: 10691080

Schnurr, JL, Ostfeld RS, Canham CD (2002) Direct and indirect effects of masting on rodent populations and tree seed survival. Oikos 96: 402-410.

Shahid, A, Garneau DE, McCay TS (2009) Selection of seeds of common native and non-native plants by granivorous rodents in the Northeastern United States. Am Midl Nat 162(1): $207-212$

Souther S, McGraw JB (2011) Local adaptation to temperature and its implications for species conservation in a changing climate. Cons Biol 25(5) 922-931

Swann DE, Haas CC, Dalton DC, Wolf SA (2004) Infrared-triggered cameras for detecting wildlife: an evaluation and review. Wildl Soc Bull 32(2) 357-365

Thuiller W, Alber C, Araújo MB, Berry PM, Cabeeza M, Guisan A, Hickler T, Midgley GF, Paterson J, Schurr FM, Sykes MT, Zimmermann NE (2008) Predicting global change 
impacts on plant species distributions: Future challenges. Perspectives in Plant Ecology, Evolution, and Systematics 9:137-152.

Vander Wall SB (2002) Masting in animal-dispersed pines facilitates seed dispersal. Ecology 83(12): 3508-3516.

Vander Wall SB (2010) How plants manipulate the scatter-hoarding behavior of seed-dispersing animals. Phil Trans R Soc B doi: 10.1098/rstb.2009.0205

Vander Wall SB, Beck MJ (2012) A comparison of frugivory and scatter-hoarding seed-dispersal syndromes. Bot Rev 78: 10-31

Wang B, Chen J (2009) Seed size, more than nutrient or tannin content, affects seed caching behavior of a common genus of Old World rodents. Ecology 90: 3023-3032

Wang B, Wang G, Chen J (2012) Scatter-hoarding rodents use different foraging strategies for seeds from different plant species. Plant Ecol 213: 1329-1336

Wolff JO (1996) Fluctuations of mast-eating rodents are correlated with production of acorns. J Mammal 77(3): 850-856 
Chapter 4: General Conclusions 


\section{Conservation Implications of Songbird and Small Mammal Interactions}

Animal interactions with seeds can have profound impacts on plant populations. Animalfacilitated dispersal can increase seedling recruitment, mediate gene flow between populations, and establish new populations, while seed predation events can negatively impact populations by decreasing seed bank input and overall seedling recruitment (Fenner 2000, Cousens et al. 2008). For many fruit-bearing plant species, it is becoming increasingly important to understand plantanimal interactions and the role they play in demographic and evolutionary processes in order to determine how species may respond to rapid environmental changes (Banks et al. 2013).

Populations of American ginseng (Panax quinquefolius L.) have been declining since the 1700s, primarily due to the intense harvest of roots for international trade (Van der Voort and McGraw 2006, McGraw et al. 2010, McGraw et al. 2013). In addition to harvest, deer browse and climate change have also been identified as environmental changes significantly contributing to population decline (McGraw and Furedi 2005, Souther and McGraw 2011, McGraw et al. 2013, Souther and McGraw in press). Dispersal of seeds could mediate negative effects caused by all three of these environmental changes by increasing gene flow between populations, reducing the presence of maladapted genes, or by establishing new populations in more advantageous sites. However, seed predation by animals removes potential new recruits from populations, contributing to population decline (Fenner 2000).

As the primary animal disperser of ginseng, thrush species (Family: Turdidae) provide the opportunity for intermediate and long distance dispersal events, which may alleviate impacts from all three threats (Chapter 2). Thrush dispersal of seeds to new safe sites may establish new populations away from deer paths and harvested populations of American ginseng (McGraw and Furedi 2005, McGraw et al. 2010). Additionally, dispersal events by thrushes to neighboring 
populations could increase gene flow between locally-adapted populations and make them more resilient climate change (Souther and McGraw 2011, Souther and McGraw in press). However, migratory thrush populations, specifically wood thrushes (Hylocichla mustenlina), have also been declining due to environmental changes, such as habitat fragmentation, acid rain, and cowbird parasitism (Trine 1998; Hames et al. 2002; Betts et al, 2010). Thus, the conservation of American ginseng is linked to the conservation of thrush populations. In order to explicitly understand how thrush dispersal may impact ginseng populations, the distances a thrush may travel within the time between ingestion and regurgitation of a seed (5-45 min) needs to be documented. More difficult to document, but also potentially important in the long-term scheme of ginseng ecology, would be the possibility for occasional very long distance dispersal for thrushes beginning their southward annual migration.

In contrast to the dispersal of ginseng seeds via thrush species, in Chapter 3 small mammals were found primarily to predate ginseng seeds. Small mammal predation has many negative implications for ginseng populations, most notably decreasing the number of seeds added to the seed bank (Fenner 2000). Decreasing the number of possible new recruits to a population can further decrease population growth and in smaller ginseng populations where fewer seeds are produced, the impacts of seed predation may be more severe. In addition, extreme seed predation, either by small mammals or deer, may prevent the recovery of a population after an unsustainable harvest.

The impacts of high masts on small mammal populations may also play an important role in ginseng dispersal potential. In chapter 3, populations that were exposed to a large range in mast indices, with high germination probabilities at either 21 or 33 mos. post-dispersal, observed decreased seedling recruitment. This suggests that at sites where germination of seeds in the 
seed bank is evenly spread out between 21,33 , and 45 mos., may be more susceptible variation in small mammal populations. Additionally, increases in small mammal populations after a mast year increase the predation of wood thrush fledglings and are correlated to the decrease of wood thrush population growth (Schmidt et al. 2008). As the primary disperser of ginseng, decreases in wood thrush populations may decrease the number of thrush-ginseng interactions.

\section{Speculative Nutritional Importance of Ginseng to Thrush Diets}

Although it can be risky to infer physiological effects of biochemical constituents across species, in the case of thrushes and ginseng, it is intriguing to consider the possibility that thrushes are attracted to ginseng berries to acquire the same 'benefits' that has led to humans adopting the plant as a natural medicinal. Ginsenosides are considered to be the chemical component found in ginseng (Genus: Panax) purported to cause the medicinal results associated with ginseng (Christensen 2008). Ginsenosides have been demonstrated to decrease hyperglycemia and thought by many to increase overall energy (Attele 2002, Lieberman 2009). Prior to migration, thrush species shift their diet from being insectivorous to frugivorous, primarily relying on sugar- and lipid-dense fruits (Willson 1994, Witmer 1996). While the chemical composition of ginseng berries was not studied as part of my thesis, ginsenosides may help provide thrush species with the energy they need for their migration. Ginsenosides may increase overall thrush energy levels, increase their activity level prior to migration, and/or increase the rate at which they can assimilate sugars, allowing them to ingest more sugar-dense fruits. These possible effects could be subject of future studies investigating the behavioral and physiological effects of ginsenosides on animal behavior. 
In game camera images, thrushes began appearing near ginseng plants prior to berries ripening and in multiple instances when thrushes interacted with ripe berries, more than one berry was removed; suggesting that thrush species may recognize ginseng as an important component of their diet. However, the decline of ginseng populations may have decreased the importance of ginseng to thrush diets. Anecdotal accounts of songbirds, such as thrushes, by naturalists and harvesters suggest that thrush-ginseng interactions may have been more common in the past than they are today.

\section{Historical Dispersal of Ginseng and Other Potential Present Day Dispersers}

The rapid and continual decline of ginseng populations throughout Appalachia, particularly the loss of reproductive individuals via harvest and deer browse, may have decreased the dispersal potential of American ginseng seeds. Decline in population size may have decreased the frequency of thrush-ginseng interactions by decreasing the number of fruits available for thrushes, forcing their diets to rely more heavily on other fruits. In addition, thrush habitat loss and fragmentation may have also caused thrushes to forage in areas where ginseng no longer exists, further decreasing their reliance on ginseng. The decline in ginseng population size may have likewise decreased the potential for small mammals to disperse seeds via scatterhoarding. During my field research, scatter-hoarding in the field was rarely observed, most likely because seeds do not occur at high densities in the wild and seeds are small so they are eaten when discovered by small mammals (e.g. Vander Wall 2010, Wang et al. 2012, Rusch et al. 2013). However, when ginseng was more abundant along the forest floor, small mammals may have been more likely to scatter-hoard seeds due to higher seed densities. This could have 
explained the caching that was observed in Van der Voort's study with 16,000 ginseng seeds (Van der Voort, 2005)

Thrushes and small mammals were the two most frequent categories of animals captured interacting with ginseng berries in game camera images, but other animals observed in images may also infrequently ingest and potentially disperse ginseng seeds. At the Tennessee Aquarium (Chapter 2), other songbirds were observed to ingest ginseng berries within the wood thrush exhibit. Most notably, Northern cardinals (Cardinalis cardinalis) were the most frequent nonthrush species to take ginseng berries. However, they predated ginseng seeds by removing both the pulp and seed coat, solely ingesting the embryo. Additionally, summer tanagers (Piranga rubra) were observed ingesting ginseng berries whole, but were never witnessed regurgitating or defecating the seeds.

Larger mammals $(>1 \mathrm{~kg})$ may also disperse ginseng seeds on rare occasions. While white-tailed deer have been shown to masticate ginseng seeds and kill the embryo (Furedi and McGraw 2004), other large mammals have been shown to pass whole seeds. For example, raccoons (Procyon lotor) are considered to be generalist omnivores that will eat a majority of food items and are less selective as food availability decreases (Rulison et al. 2012). Whole seeds are frequently seen in raccoon scat. Additionally, during the early fall, black bears (Ursus americanus) ingest many fruits similar to American ginseng, such as black cherries (Prunus serotina) (Beeman and Pelton 1977), again passing the seeds through their digestive systems. If bears are foraging along the ground for fruit species, it is possible that they may ingest ginseng berries after they have fallen from the infructescence and may act as a secondary mode of dispersal after seeds are dispersed via gravity. 


\section{Conclusion}

To date, gravity has been considered to be the primary mechanism of ginseng dispersal (Lewis and Zenger 1982, Van der Voort 2005). However, my thesis suggests that animal dispersal, particularly by thrushes, may be more frequent than previously considered. Future research investigating thrush movements during the late summer/early fall will help to create a comprehensive understanding of the role of thrush dispersal in the maintenance of gene flow and future distribution of ginseng. Specifically, by understanding the distances that thrushes travel within the average regurgitation time would help parameterize a spatially-explicit distribution model for American ginseng, a long term goal for understanding ginseng demography and conserving the species. Additionally, small mammals have been identified as a group of animals that may have historically played an important role in dispersal, but today primarily predate ginseng seeds; contributing to the decrease in population growth. 


\section{Literature Cited}

Attele, A. S., Y. Zhou, J. Xie, J. A. Wu, L. Zhang, L. Dey, W. Pugh, P. A. Rue, K. S. Polonsky, and C. Yuan. 2002. Antidiabetic effects of Panax ginseng berry extract and the identification of an effective component. Diabetes 51(6): 1851-1858.

Banks, S. C., G. J. Cary, A. L. Smith, I. D. Davies, D. A. Driscoll, A. M. Gill, D. B. Lindenmayer, and R. Peakall. 2013. How does ecological disturbance influence genetic diversity. Trends in Ecology and Evolutionary Biology 28(11): 670-679.

Beeman, L. E. and M. R. Pelton. 1977. Season foods and feeding ecology of black bears in the Smoky Mountains. Bears: Their Biology and Management 4: 141-147.

Betts, M. G., J. C. Hagar, J. W. Rivers, J. D. Alexander, K. McGarigal, and B. C. McComb. 2010. Thresholds in forest bird occurrence as a function of the amount of early-seral broadleaf forest at landscape scales. Ecological Applications 20(8): 2116-2130.

Christensen, L. P. 2008. Chapter 1: Ginsenosides: chemistry, biosynthesis, analysis, and potential health effects. Advances in Food and Nutrition Research 55: 1-99.

Lieberman, H. R. 2001. The effects of ginseng, ephedrine, and caffeine on genitive performance, mood, and energy. Nutrition Reviews 59(4): 91-102.

Cousens, R., C. Dytham, and R. Law. 2008. Dispersal in plants: A population perspective. Oxford University Press, Oxford, United Kingdom.

Fenner, M. (ed.) 2000. Seeds: The ecology of regeneration in plant communities, 2 edn. CAB International, Wallingford, UK.

Furedi, M. A. and J. B. McGraw. 2004. White-tailed deer: dispersers or predators of American ginseng seeds? Amercian Naturalist 152: 268-276.

Hames, R. S., K. V. Rosenburg, J. D. Lowe, S. E. Barker, and A. A. Dhondt. 2002. Adverse 
effects of acid rain on the distribution of the wood thrush Hylocichla mustelina in North America. Proceedings of the National Academy of Sciences 99(17): 11235-11240.

Johannsen, K. 2006. The Secret World of America's Most Valuable Plant. The University Press, Lexington, Kentucky, United States of America.

Lewis, W. H. \& V. E. Zenger, 1982. Dynamics of American ginseng Panax quinquefolium (Araliaceae). American Journal of Botany, 69(9): 1483-1490.

McGraw J. B and M. A. Furedi. 2005. Deer browsing and population viability of a forest understory plant. Science 307: 920-922

McGraw, J. B., A. E. Lubbers, M. E. Van der Voort, E. H. Mooney, M. A. Furedi, S. Souther, J. B. Turner, J. Chandler. 2013. Ecology and conservation of ginseng (Panax quinquefolius) in a changing world. Annals of the New York Academy of Sciences 1286(1): 62-91.

Rulison, E. L., L. Luiselli, and R. L. Burke. 2012. Relative impacts of habitat and geography on raccoon diets. The American Midland Naturalist 168(2) 231-246.

Rusch U. D., J. J. Midgley, and B. Anderson2013.Rodent consumption and caching behavior selects for specific seed traits. South African Journal of Botany 84: 83-87

Souther, S. and J. B. McGraw. 2011. Local adaptation to temperature and its implications for species conservation in a changing climate. Conservation Biology 25(5)922-931.

Souther, S. and J. B. McGraw. in press. Synergistic effects of climate change and harvest on extinction risk of American ginseng. Ecological Applications.

Trine, C. L. 1998. Wood thrush population sinks and implications for the scale of regional conservation strategies. Conservation Biology 12(3): 576-585.

Wang B. , G. Wang, J. Chen. 2012. Scatter-hoarding rodents use different foraging strategies for seeds from different plant species. Plant Ecology 213: 1329-1336 
Willson, M. F. 1994. Choices by captive American robins. The Condor 96(2): 494-502.

Witmer, M. C. 1996. Annual diet of cedar waxwings based on U.S. Biological Survey records (1885-1950) compared to diet of American robins: contrasts in dietary patterns and natural history. The Auk 113(2): 414-430.

Vander Wall S. B. 2010. How plants manipulate the scatter-hoarding behavior of seed-dispersing animals. Philosophical Transactions of the Royal Society of Biological Sciences doi: 10.1098/rstb.2009.0205

Van der Voort, M. E.. 2005. An ecological and demographic study of American ginseng (Panax quinquefolius L.) in central Appalachia. Ph.D. dissertation, West Virginia University, Morgantown, West Virginia.

Van der Voort, M. E., J. B. McGraw. 2006. Effects of harvester behavior on population growth and affects sustainability of ginseng trade. Biological Conservation 130: 505-516 